\title{
Reavaliação das características morfológicas e suas implicações taxonômicas no gênero Polysiphonia sensu lato (Ceramiales, Rhodophyta) do litoral dos Estados de São Paulo e Espírito Santo, Brasil
}

\author{
SILVIA M.P.B. GUIMARÃES ${ }^{1,2}$, MUTUE T. FUJII' ${ }^{1}$, DICLÁ PUPO ${ }^{1}$ e NAIR S. YOKOYA ${ }^{1}$
}

(recebido: 26 de dezembro de 2002; aceito: 20 de novembro de 2003)

\begin{abstract}
An assessment of the morphological characteristics and its taxonomical implication in the genus Polysiphonia sensu lato (Ceramiales, Rhodophyta) from the littoral of São Paulo and Espírito Santo States, Brazil). The genus Polysiphonia Grev. has a wide circunscription and is heterogeneous in vegetative and reproductive features. This paper presents a detailed study of the genus Polysiphonia sensu lato occurring at São Paulo and Espirito Santo States, Brazil, and an assessment of its morphological characteristics taking into consideration the recent taxonomic criteria, which led to the subdivision of that genus in Polysiphonia and Neosiphonia M.-S. Kim \& I.K. Lee. In the present paper five species of Polysiphonia and six species of Neosiphonia were studied. Neosiphonia ferulacea (Suhr ex J. Agardh) S.M. Guim. \& M.T. Fujii, N. gorgoniae (Harv.) S.M. Guim. \& M.T. Fujii and N. tepida (Hollenb.) S.M. Guim. \& M.T. Fujii are proposed as new combinations. Neosiphonia harveyi (Bailey) M.-S. Kim, H.-G. Choi, Guiry \& G.W. Saunders is referred for the first time to the South Atlantic. This represents an uncommon occurrence since this species is considered member of the cold temperate North Atlantic flora and most of the species of Polysiphonia sensu lato so far described to Brazil have been associated to the tropical and subtropical conditions.
\end{abstract}

Key words - Ceramiales, Neosiphonia, Polysiphonia, Rhodophyta, taxonomy

RESUMO - (Reavaliação das características morfológicas e suas implicações taxonômicas no gênero Polysiphonia sensu lato (Ceramiales, Rhodophyta) do litoral dos Estados de São Paulo e Espírito Santo, Brasil). O gênero Polysiphonia Grev. tem uma circunscrição ampla e é heterogêneo em características vegetativas e reprodutivas. O presente trabalho visa o estudo detalhado e a reavaliação das espécies de Polysiphonia sensu lato que ocorrem nos Estados do Espírito Santo e São Paulo, tendo em vista os critérios taxonômicos recentes, que levaram à subdivisão do gênero em Polysiphonia e Neosiphonia M.-S. Kim \& I.K. Lee. Neste trabalho, são estudadas cinco espécies de Polysiphonia e seis espécies de Neosiphonia, sendo que Neosiphonia ferulacea (Suhr ex J. Agardh) S.M. Guim. \& M.T. Fujii, N. gorgoniae (Harv.) S.M. Guim. \& M.T. Fujii e N. tepida (Hollenb.) S.M. Guim. \& M.T. Fujii são propostas como combinações novas. Neosiphonia harveyi (Bailey) M.-S. Kim, H.-G. Choi, Guiry \& G.W. Saunders é referida pela primeira vez para o Atlântico Sul, representando uma ocorrência incomum, por ser integrante da flora temperada fria do Atlântico Norte, enquanto as demais espécies de Polysiphonia sensu lato descritas para o Brasil estão relacionadas a condições tropicais e subtropicais.

Palavras-chave - Ceramiales, Neosiphonia, Polysiphonia, Rhodophyta, taxonomia

\section{Introdução}

Polysiphonia Grev. é um dos gêneros de algas vermelhas mais amplamente distribuídos no mundo, com mais de 150 espécies descritas (Kim \& Lee 1999). O gênero tem uma circunscrição ampla e é heterogêneo em características vegetativas e reprodutivas (Maggs \& Hommersand 1993).

A identificação das espécies de Polysiphonia tem sido baseada principalmente em características vegetativas, tais como número de células pericentrais por segmento axial, origem dos rizóides, dos ramos e

\footnotetext{
1. Instituto de Botânica, Seção de Ficologia, Caixa Postal 4005, 01061-970 São Paulo, SP, Brasil.

2._Autor para correspondência: smpbguimaraes@uol.com.br
}

dos corpos espermatangiais, na freqüência de tricoblastos e da célula-cicatriz dos mesmos, no arranjo dos tetrasporângios e em detalhes das células do pericarpo. Estas características diagnósticas foram descritas para espécies do Atlântico tropical e subtropical da América do Norte (Schneider \& Searles 1991), Carolina do Norte (Kapraun 1977), Golfo do México (Kapraun 1979), Belize (Kapraun \& Norris 1982), Colômbia e Venezuela (Kapraun et al. 1983). Quinze espécies de Polysiphonia foram referidas até o momento para o Brasil (Oliveira Filho 1977, Yoneshigue \& Villaça 1986).

Apesar do gênero Polysiphonia ser separado dos outros membros da família Rhodomelaceae, pelo menos em parte, pela sua simetria radial e hábito ereto (Hollenberg 1942), a maioria das espécies apresenta, em algum grau, um dos três tipos de desenvolvimento 
de eixo prostrado discutidos por Kapraun (1977): i) plantas inicialmente eretas a partir de uma base discóide, porém formando uma fixação rizoidal secundária a partir de ramos decumbentes; ii) plantas desenvolvendo um sistema horizontal derivado de um ápice ereto; iii) plantas desenvolvendo um sistema prostrado a partir de um ápice disposto na horizontal.

Recentemente, Kim \& Lee (1999) estudaram o gênero Polysiphonia da costa ocidental da Coréia e transferiram parte das espécies para um novo gênero, Neosiphonia M.-S. Kim \& I.K. Lee. Neosiphonia (espécie-tipo: N. flavimarina M.-S. Kim \& I.K. Lee) apresenta as seguintes características: i) iniciais de ramos laterais, incluindo as iniciais de tricoblastos, produzidas em segmentos sucessivos; ii) ausência de um sistema basal prostrado extenso, podendo apresentar uma base discóide ou um sistema prostrado derivado de um ápice ereto; iii) rizóides originados por divisão da célula pericentral (conexão fechada); iv) tricoblastos abundantes; v) ramo carpogonial com três células; vi) ramos espermatangiais originados a partir de um ramo do tricoblasto; vii) tetrasporângios com arranjo espiral. Por outro lado, Polysiphonia (espécietipo: P. urceolata (Dillwyn) Grev.), como concebido por Kim \& Lee (1999), apresenta as seguintes características: i) iniciais de ramos laterais não produzidas em segmentos sucessivos; ii) presença de um sistema basal prostrado extenso derivado de um ápice disposto na horizontal; iii) rizóides originados pelo prolongamento da célula pericentral (conexão aberta); iv) tricoblastos raros ou ausentes; v) ramo carpogonial com quatro células; vi) ramos espermatangiais originados de inicial de ramo lateral; vii) tetrasporângios com arranjo em linha reta.

Dentre as espécies de Polysiphonia referidas para a Coréia, 11 foram transferidas para Neosiphonia (Kim \& Lee 1999). Entre estas, Polysiphonia flaccidissima Hollenb. e P. sphaerocarpa Børgesen, que também ocorrem no Atlântico, passaram para Neosiphonia flaccidissima (Hollenb.) M.-S. Kim \& I.K. Lee e N. sphaerocarpa (Børgesen) M.-S. Kim \& I.K. Lee. Com base em material da Irlanda, $P$. harveyi Bailey foi transferida para $N$. harveyi (Bailey) M.-S. Kim, H.-G. Choi, Guiry \& G.W. Saunders (Choi et al. 2001).
Apesar do gênero Polysiphonia ter sido incluído nas floras regionais do Brasil, falta um estudo crítico da maioria das espécies. Em estudo sobre a flora marinha dos Estados do Espírito Santo e São Paulo, visando incrementar o conhecimento da diversidade, foi possível fazer uma avaliação das espécies de Polysiphonia encontradas nos dois estados e uma análise comparativa com as espécies anteriormente referidas para a região sudeste do Brasil.

Para a região sudeste do Brasil, as seguintes espécies são referidas: Neosiphonia flaccidissima (como Polysiphonia flaccidissima), N. sphaerocarpa (como P. sphaerocarpa), P. decussata Hollenb., P. denudata (Dillwyn) Grev. ex Harv. in Hook., P. eastwoodae Setch. \& N.L Gardner, P. ferulacea Suhr ex J. Agardh, P. gorgoniae Harv., P. havanensis Mont., P. howei Hollenb., P. macrocarpa Harv., P. saccorhiza (Collins \& Herv.) Hollenb., P. scopulorum Harv. var. scopulorum e var. villum (J. Agardh) Hollenb., P. subtilissima Mont. e P. tepida Hollenb. (Joly 1957, 1965, Oliveira Filho 1969, Ugadim 1976, Yoneshigue 1985, Yoneshigue \& Villaça 1986, Figueiredo 1989, Amado Filho 1991, Horta 2000).

O presente trabalho visa o estudo detalhado das espécies de Polysiphonia sensu lato (Polysiphonia e Neosiphonia) que ocorrem nos Estados do Espírito Santo e São Paulo e uma reavaliação das características morfológicas utilizando os novos critérios taxonômicos propostos por Kim \& Lee (1999).

\section{Material e métodos}

As amostras para o presente estudo foram coletadas nos Estados do Espírito Santo e São Paulo. A maioria das amostragens foi realizada na região entremarés e algumas entre 5-12 m de profundidade, no litoral de São Paulo.

Os estudos foram realizados com material preservado em formol a $4 \%$ em água do mar e corado com solução aquosa de azul de anilina a 0,5\%, acidificada com $\mathrm{HCl} 1 \mathrm{~N}$. As ilustrações das características morfológicas foram feitas através de fotografias e/ou fotomicrografias sob microscópio Olympus BH-2, usando o filme T-MAX, ASA 100. Desenhos em câmara-clara complementam as ilustrações. O material encontra-se depositado no Herbário "Maria Eneyda P.K. Fidalgo" do Instituto de Botânica, São Paulo, Brasil (SP). 


\section{Resultados}

\section{Chave de identificação das espécies de Neosiphonia e Polysiphonia}

1. Iniciais de ramos laterais, incluindo as iniciais de tricoblastos, produzidas em segmentos sucessivos; ausência de um sistema basal prostrado extenso, mas apresentando uma base discóide ou um sistema prostrado derivado de um ápice ereto; rizóides originados por divisão da célula pericentral, ou seja, com conexão fechada; tricoblastos geralmente abundantes; ramo carpogonial com três células; ramos espermatangiais originados a partir de um ramo do tricoblasto; tetrasporângios com arranjo em espiral

Neosiphonia

2. Com 7 a 8 células pericentrais por segmento axial

N. tepida

2. Com 4 células pericentrais por segmento axial

3. Talo ereto com disco basal de fixação, sistema prostrado ausente

4. Plantas ecorticadas

N. gorgoniae

4. Plantas corticadas na base N. harveyi

3. Talo ereto sem disco basal de fixação, sistema prostrado presente

5. Ramos formando-se na axila dos tricoblastos N. flaccidissima

5. Ramos substituindo os tricoblastos

6. Plantas delicadas, menores que $2 \mathrm{~cm}$ de altura, segmentos aproximadamente tão largos quanto longos e com 100-185 $\mu \mathrm{m}$ de diâmetro na região mediana N. sphaerocarpa

6. Plantas robustas, maiores que $2 \mathrm{~cm}$ de altura, segmentos cerca de duas vezes mais largos que longos em toda extensão do talo e com mais de $200 \mu \mathrm{m}$ de diâmetro na região mediana.

N. ferulacea

1. Iniciais de ramos laterais não produzidas em segmentos sucessivos; ramos eretos desenvolvidos a partir de um sistema basal prostrado extenso com o ápice disposto na horizontal (exceto em $P$. cf. denudata); rizóides originados pelo prolongamento da célula pericentral, ou seja, com conexão aberta (exceto em $P$. cf. denudata e em $P$. howei); tricoblastos geralmente raros ou ausentes; ramo carpogonial com quatro células; ramos espermatangiais originados de inicial de ramo lateral; tetrasporângios com arranjo em linha reta (exceto em $P$. howei)

7. Com mais de 4 células pericentrais por segmento axial

8. Com 5 a 6 células pericentrais por segmento axial. Polysiphonia

8. Com 9 a 14 células pericentrais por segmento axial P. cf. denudata

7. Com 4 células pericentrais por segmento axial

9. Plantas com ramos laterais regularmente distribuídos, com ramificação alterno-dística em intervalos de 4 segmentos, conferindo um aspecto "penado" à fronde P. decussata

9. Plantas apresentando ramos laterais não dispostos regularmente de maneira alterno-dística

10. Plantas maiores que $1 \mathrm{~cm}$, eixo prostrado originando ramos eretos em várias direções, ramos eretos muito ramificados, segmentos com diâmetro sucessivamente menor em direção ao ápice .... P. subtilissima

10. Plantas menores que $1 \mathrm{~cm}$, eixo prostrado originando ramos eretos unilateralmente, ramos eretos raramente ramificados, segmentos com diâmetro aproximadamente igual em toda extensão do talo P. scopulorum

\section{Gênero Neosiphonia}

Neosiphonia ferulacea (Suhr ex J. Agardh) S.M. Guim. \& M.T. Fujii, comb. nov.

Basônimo: Polysiphonia ferulacea Suhr ex J. Agardh, Species Genera et Ordines Algarum 3(2):980. 1863.

Figuras 1-5.
Plantas robustas crescendo sobre rocha, vináceas. Sistema basal prostrado reduzido, fixo por numerosos rizóides proximais, dando origem a eixos eretos de crescimento indeterminado de até $3 \mathrm{~cm}$ alt.; eixos prostrados 240-350 $\mu \mathrm{m}$ diâm., ecorticados, segmentos cerca de duas vezes mais largos que longos em toda extensão do eixo, com 4 células pericentrais. Eixos eretos 
com ramificação alterna, segmentos duas vezes mais largos que longos em toda a extensão, região basal

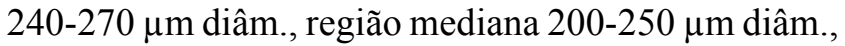
região superior (décimo segmento abaixo da célula apical) 80-90 $\mu \mathrm{m}$ diâm.; tricoblastos e cicatrizes de tricoblastos raros. Ramos substituindo tricoblastos na seqüência de desenvolvimento do ápice. Tetrasporângios com $85 \mu \mathrm{m}$ diâm., em espiral. Plantas sexuadas não observadas.

Material examinado: BRASIL: EsPíRITO SANTO: Linhares, Barra Seca, 17-VIII-1986, infértil, tetraspórica, S.M.P.B. Guimarães et al. s.n. (SP355472); Fundão, Enseada das Garças, 29-VII-2003, infértil, S.M.P.B. Guimarães et al. s.n. (SP355785).

Distribuição: Atlântico: Carolina do Norte, Flórida, Caribe, Brasil, Portugal, Espanha, África tropical. Pacífico: Austrália, Havaí. Índico: região norte do Índico, Ilhas Maurício, Ilhas Seychelles, Tanzânia. (Localidades sintipo: Atlântico mexicano, América do Norte, Guadalupe, Índias Ocidentais, Havaí, Ilhas Marquesas, Austrália).

Este material corresponde às plantas mais robustas dentre as coletadas na região Sudeste do Brasil. Foram coletadas sobre arenitos em estações de coleta situadas ao norte de Vitória, ES. Concordam com a descrição de Børgesen (1918) para Polysiphonia ferulacea. As dimensões dos eixos estão de acordo com os dados de Schneider \& Searles (1991), exceto pela posição dos rizóides que estes autores descrevem como distal. Børgesen (1918) mencionou que Neosiphonia sphaerocarpa é muito semelhante a $N$. ferulacea (ambas como Polysiphonia), exceto por ser uma planta mais delicada.

As plantas consideradas neste trabalho como Neosiphonia sphaerocarpa, muito comuns tanto no Espírito Santo como em São Paulo, foram comparadas detalhadamente com $N$. ferulacea e verificou-se que apresentam o diâmetro do talo e o tamanho das células correspondendo aproximadamente à metade das medidas das plantas de Barra Seca e da Enseada das Garças (figura 5).

Neosiphonia ferulacea (como Polysiphonia ferulacea) foi descrita anteriormente para a região Sudeste por Joly (1965), Oliveira Filho (1969), Yoneshigue (1985) e Horta (2000). Entretanto, pelas medidas apresentadas por estes autores (com exceção de Horta 2000, que não apresenta descrição e nem medidas), concluímos que estas plantas correspondem, de fato, a Neosiphonia sphaerocarpa. O material de Ubatuba (SPF 3758), estudado e identificado por Joly (1965), foi reestudado e verificou-se que o talo apresenta diâmetro na região mediana de $165 \mu \mathrm{m}$ e células pouco mais longas que largas, correspondendo, também, a $N$. sphaerocarpa. As medidas apresentadas por Yoneshigue (1985) para as duas espécies (como $P$. ferulacea e $P$. sphaerocarpa) confirmam as diferenças nas dimensões do talo. Materiais do Estado de Santa Catarina (SP113597) e do Ceará (SPF3757) foram também revistos e apresentaram os segmentos da região mediana com mais de $200 \mu \mathrm{m}$ e células bem mais largas que longas, correspondendo a $N$. ferulacea.

Neosiphonia flaccidissima (Hollenb.) M.-S. Kim \& I.K. Lee, Phycol. Res. 47:279. 1999. $\equiv$ Polysiphonia flaccidissima Hollenb., Amer. J. Bot. 29:783. 1942. Figuras 6-8.

Plantas crescendo sobre rocha ou epífitas, marrons, com um sistema prostrado derivado de um ápice ereto, formando tapetes densos; rizóides proximais. Eixos eretos de crescimento indeterminado de até $1,0 \mathrm{~cm}$ alt.; eixos prostrados bem mais largos que os eretos, 94-164 um diâm., ecorticados, segmentos pouco mais longos que largos, com 4 células pericentrais. Eixos eretos sem diferenciação de um eixo principal, região basal 80-85 $\mu \mathrm{m}$ diâm., região mediana 49-63 $\mu \mathrm{m}$ diâm., segmentos pouco mais longos que largos; ramos laterais curtos saindo na axila de tricoblastos, dispostos em espiral, em intervalos de 6-10 segmentos. Tricoblastos numerosos, com ca. 2 dicotomias ou ausentes. Célulacicatriz de tricoblastos bem visível em alguns ramos. Ramos adventícios curtos endógenos também presentes. Tetrasporângios 50-65 $\mu \mathrm{m}$ diâm., em espiral. Plantas masculinas não observadas. Cistocarpos ovóides, 180-200 $\mu \mathrm{m}$ diâm.

Material examinado: BRASIL: EsPíRIto SANTo: Guarapari, Peracanga-Guaibura, 4-VII-1985, infértil, S.M.P.B. Guimarães et al. s.n. (SP355473); 13-VI-1995, tetraspórica, S.M.P.B. Guimarães et al. s.n (SP355502); 18-V-1999, tetraspórica, S.M.P.B. Guimarães et al. s.n. (SP355474); Itapemirim, Ilha do Francês, 2-V-1985, feminina, tetraspórica, S.M.P.B. Guimarães et al. s.n. (SP355734). São Paulo: Ubatuba, Enseada do Flamengo, 9-IV-2001, infértil, M.T.Fujii et al. s.n. (SP336663, SP336815); Ilhabela, Ilha Vitória, 5-9 m profundidade, 13-III-2001, infértil, G. Amado Filho et al. s.n. (SP336623), Baía dos Castelhanos, Saco do Eustáquio, 15-X-2001, feminina, infértil, S.M.P.B. Guimarães et al. s.n. (SP336817).

Distribuição: Atlântico: Carolina do Norte, Bermudas, Brasil. Pacífico Tropical, Coréia, Califórnia (localidade-tipo Laguna Beach). 


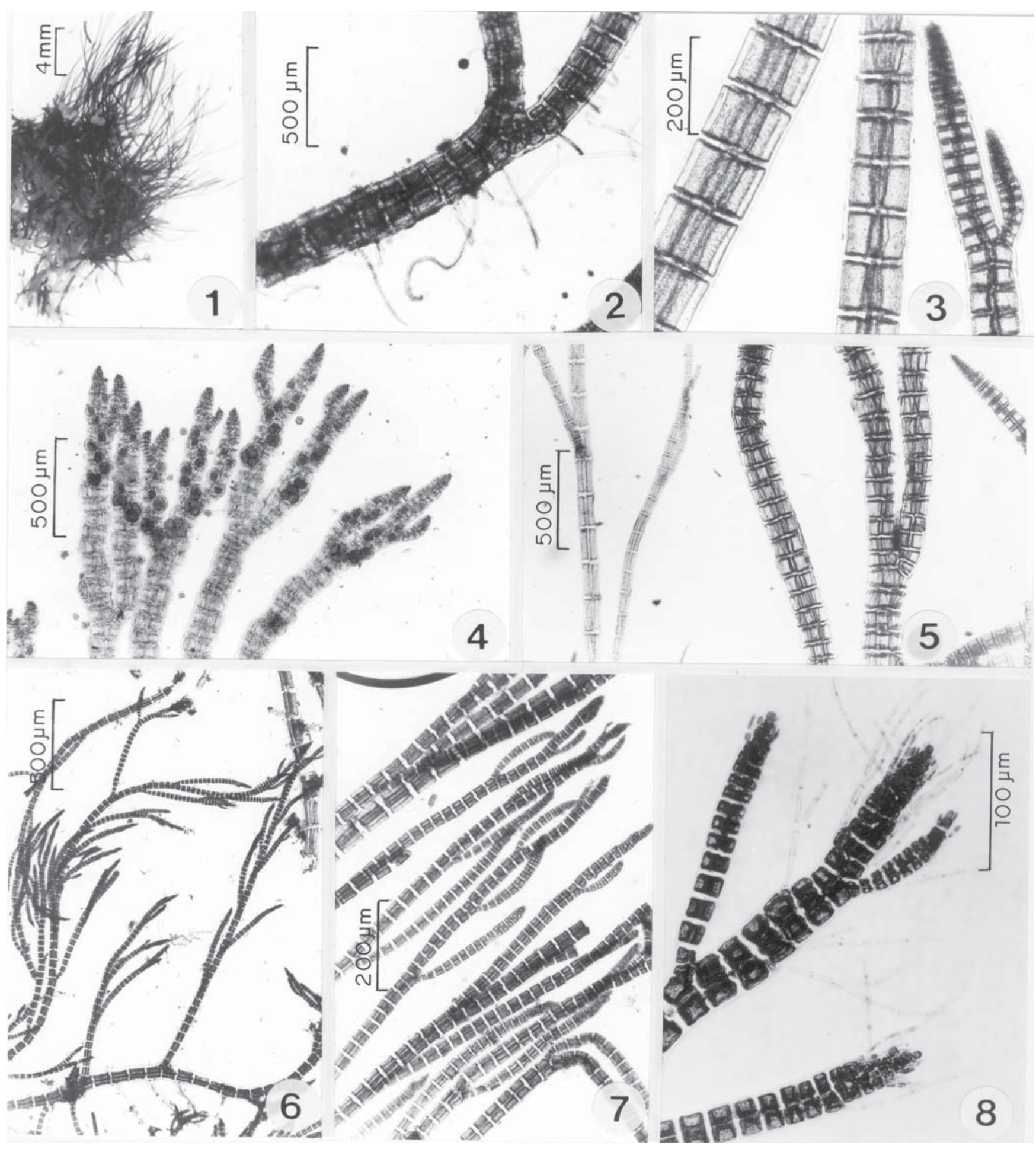

Figuras 1-5. Neosiphonia ferulacea. 1. Hábito. 2. Eixo com parte prostrada e parte ereta. 3. Detalhe dos segmentos mais largos que altos. 4. Fronde tetraspórica. 5. Comparação entre as dimensões dos segmentos de $N$. ferulacea (planta robusta à direita) e N. sphaerocarpa (planta delicada à esquerda). Figuras 6-8. Neosiphonia flaccidissima. 6. Hábito. 7. Detalhe dos eixos eretos com ramos laterais curtos. 8. Ápices com tricoblastos.

Figures 1-5. Neosiphonia ferulacea. 1. Habit. 2. Prostrate and erect part of the axis. 3. Detail of the segments broader than long. 4. Tetrasporic plant. 5. Comparison between the size of the segments of $P$. ferulacea (robust plant on the right) and P. sphaerocarpa (delicated plant on the left). Figures 6-8. Neosiphonia flaccidissima. 6. Habit. 7. Detail of upper portion of the axes showing short lateral branches.8. Apices with trichoblasts. 
Como epífita, este táxon ocorre principalmente sobre espécies de Padina, Sargassum, Laurencia, coralináceas articuladas, Codium e sobre Dasya brasiliensis E.C. Oliveira \& Y. Braga e Plocamium brasiliense (Grev. in J. St.-Hil.) M. Howe \& W.R. Taylor.

A espécie caracteriza-se pelo porte pequeno, rizóides proximais e ramos originando-se na axila dos tricoblastos. Os eixos eretos apresentam ramos laterais curtos no ápice, à primeira vista, lembrando a espécie Polysiphonia decussata. Entretanto, nesta, os ramos curtos são regularmente originados a cada 4-5 segmentos e em Neosiphonia flaccidissima os ramos curtos são mais irregulares e originados a cada 6-10 segmentos.

Hollenberg (1968) reconheceu quatro variedades neste táxon, baseando-se principalmente no diâmetro dos eixos eretos e na freqüência dos ramos laterais. Porém, no material brasileiro, não se reconheceu variedades. Segundo Hollenberg (1942), Neosiphonia flaccidissima (como Polysiphonia flaccidissima) é similar à espécie Polysiphonia havanensis ilustrada por Børgesen (1918, figuras 260, 261) para as Índias Ocidentais que, entretanto, é um exemplar maior, com eixos principais distintos e rizóides em conexão aberta com a pericentral. Searles \& Schneider (1991) e Kapraun et al. (1983) enfatizaram estas diferenças entre as duas espécies. O material de $N$. flaccidissima, estudado neste trabalho, concorda em linhas gerais com os dados de Yoneshigue \& Villaça (1986, como P. flaccidissima), para plantas da região de Cabo Frio (RJ).

Polysiphonia havanensis foi referida para o Espírito Santo por Oliveira Filho (1969) e para São Paulo por Ugadim (1970). Estes autores não levaram em consideração o tipo de rizóide e, baseados na observação da origem dos ramos na axila dos tricoblastos, identificaram o material como $P$. havanensis. O material estudado por Ugadim (1970), da Ilha do Bom Abrigo, São Paulo (SPF 1355), foi reestudado e identificado como Neosiphonia flaccidissima. O material referido por Oliveira Filho (1969), coletado nos costões de Peracanga-Guaibura, ES, não estava disponível em herbário. Entretanto, estes locais correspondem aos mesmos onde coletamos a maior parte de material de N. flaccidissima. Dessa forma, consideramos que o material referido por Oliveira Filho (1969) como $P$. havanensis, deve corresponder a $N$. flaccidissima.

Neosiphonia flaccidissima é também similar a $N$. sphaerocarpa, diferindo desta por apresentar tricoblastos persistentes e ramos laterais originados na axila dos tricoblastos.
Neosiphonia gorgoniae (Harv.) S.M. Guim. \& M.T. Fujii, comb. nov.

Basônimo: Polysiphonia gorgoniae Harv., Smithsonian Contr. Knowl. 5(5):39. 1853.

Figuras 9-13.

Plantas epífitas, marrons, com disco basal de fixação composto por tufo de rizóides, sem eixos prostrados. Eixos eretos de crescimento indeterminado de até 3,0 cm alt., segmentos ecorticados, tão largos quanto altos, com 4 células pericentrais. Eixos principais 160-270 $\mu \mathrm{m}$ diâm. na base e $130-230 \mu \mathrm{m}$ diâm. na região mediana. Redução drástica no diâmetro dos eixos em direção aos ápices, porções superiores com $1 / 5$ do diâmetro da base. Ramificação alterna em ângulo menor que $90^{\circ}$. Ramos substituindo tricoblastos na seqüência de desenvolvimento do ápice; tricoblastos escassos, células-cicatriz de tricoblastos em todos os segmentos. Tetrasporângios ca. $100 \mu \mathrm{m}$ diâm., em espiral. Corpos espermatangiais com 170-200 $\mu \mathrm{m}$ compr., originados a partir de um ramo do tricoblasto e terminando em uma célula estéril. Ramo carpogonial com 3 células. Cistocarpos ovóides, 160-250 $\mu \mathrm{m}$ diâm. e 240-290 $\mu \mathrm{m}$ alt., com pedúnculo curto.

Material examinado: BRASIL: EspíRITo SANTo; Vitória, Praia de Camburi, III-2002, feminina, masculina, tetraspórica, J.P. Alves s.n. (SP355475); Vila Velha, Ponta da Fruta, 9-III-1986, feminina, tetraspórica, S.M.P.B. Guimarães et al. s.n. (SP355476); Itapemirim, Itaoca/Itaipava, 13-III-1986, feminina, tetraspórica, S.M.P.B. Guimarães et al. s.n. (SP318146); Marataízes, 8-III-1986, feminina, S.M.P.B. Guimarães et al. s.n. (SP355477). SÃo PAULO: Ubatuba, Ilha das Couves, 5-XI-1999, feminina, S.M.P.B. Guimarães et al. s.n. (SP336152); Santos, Laje de Santos, $11 \mathrm{~m}$ profundidade, 20-X-2001, feminina, masculina, G. Amado Filho \& M.B.B. Barreto s.n. (SP355733).

Distribuição: Atlântico: Flórida (localidade-tipo), Brasil. Índico: Ilhas Mauricio.

Ocorre principalmente sobre espécies de Padina, Sargassum, Bryocladia, Spyridia, coralináceas articuladas, Codium e sobre Dasya brasiliensis E.C. Oliveira \& Y. Braga.

Espécie característica por apresentar uma base discóide, formada por tufo de rizóides, o que a diferencia das demais espécies, exceto de Neosiphonia harveyi.

No Brasil, até o presente, Neosiphonia gorgoniae está referida somente para as regiões Sudeste e Sul do do país. 
Neosiphonia harveyi (Bailey) M.-S. Kim, H.-G. Choi, Guiry \& G.W. Saunders, Can. J. Bot. 79:1474. 2001. $\equiv$ Polysiphonia harveyi Bailey, Amer. J. Sci. Arts, ser. 2, 6:38. 1848.

Figuras 14-16.

Plantas crescendo sobre cordas de embarcação, associadas a Neosiphonia gorgoniae, marrons ou enegrecidas, com disco basal de fixação composto de aglomerado de rizóides, sem eixos prostrados. Eixos eretos de crescimento indeterminado de até $2,0 \mathrm{~cm}$ alt., segmentos ca. 2 vezes mais largos que altos, com 4 células pericentrais. Eixos principais rígidos $500-700 \mu \mathrm{m}$ diâm. na base e 120-170 $\mu \mathrm{m}$ na região mediana. Ramificação alterna em ângulo maior que $90^{\circ}$, escassa na região basal e densa nas regiões superiores. Ramos substituindo tricoblastos na seqüência de desenvolvimento do ápice; tricoblastos escassos ou ausentes. Cicatriz de tricoblasto presente. Pequena corticação na base dos eixos principais, iniciada a partir de divisão oblíqua na extremidade proximal de cada célula pericentral. Tetrasporângios ca. $50 \mu \mathrm{m}$ diâm., em espiral. Plantas sexuadas não observadas.

Material examinado: BRASIL: SÃo PAulo: Ubatuba, Praia de Itaguá, 16-XI-97, tetraspórica, S.M.P.B. Guimarães \& N.S. Yokoya s.n. (SP 355478).

Distribuição: Atlântico: da Nova Escócia até a Carolina do Sul (localidade-tipo Stonington, Connecticut). Brasil. Noruega, Dinamarca, Helgoland, noroeste da França. Ilhas Britânicas.

Esta espécie foi coletada apenas uma vez, em cordas de embarcação. Difere das outras espécies por apresentar uma base discóide e uma pequena corticação na base dos eixos principais. Concorda com a descrição apresentada por Maggs \& Hommersand (1993) (como Polysiphonia harveyi). A corticação na base dos eixos consiste de células originadas a partir da extremidade proximal das células pericentrais e que crescem entre as mesmas. Esta é a primeira referência da espécie para o Brasil e para o Atlântico Sul.

Neosiphonia sphaerocarpa (Børgesen) M.-S. Kim \& I.K. Lee, Phycol. Res. 47:280. 1999. 三 Polysiphonia sphaerocarpa Børgesen, Dansk Botanisk Arkiv 3:271. 1918.

Figuras 17-22.

Plantas crescendo sobre rocha ou epífitas, vináceas. Sistema basal prostrado reduzido, fixo por numerosos rizóides proximais, dando origem a eixos eretos de crescimento indeterminado de até $2 \mathrm{~cm}$ alt. Eixos prostrados 160-290 $\mu \mathrm{m}$ diâm., ecorticados, segmentos mais longos que largos, com 4 células pericentrais. Ramos inferiores dos eixos eretos tornando-se decumbentes e fixos secundariamente ao substrato. Eixos eretos diminuindo de diâmetro para o ápice, na região basal 200-250 $\mu \mathrm{m}$ diâm., região mediana 100-185 $\mu \mathrm{m}$ diâm., segmentos aproximadamente tão largos quanto altos, tricoblastos curtos ou mais longos, com até 3 dicotomias ou não ramificados, ausentes em algumas amostras. Ramos substituindo tricoblastos na seqüência de desenvolvimento do ápice. Célula-cicatriz de tricoblastos em todos os segmentos dos ramos eretos. Tetrasporângios 50-62 $\mu \mathrm{m}$ diâm., em espiral. Espermatângios cilíndricos, originados a partir de um ramo do tricoblasto, 26-52 $\mu \mathrm{m}$ diâm. e 100-120 $\mu \mathrm{m}$ compr., com uma célula basal e uma ou duas células estéreis no ápice. Ramo carpogonial com 3 células. Cistocarpos ovóides, 250-320 $\mu$ m diâm., com pedúnculo curto.

Material examinado: BRASIL: EsPírIto SANTo: Guarapari, Peracanga-Guaibura, 1-IX-1985, tetraspórica, S.M.P.B. Guimarães et al. s.n. (SP355505); 18-V-1999, feminina, masculina, tetraspórica, S.M.P.B. Guimarães et al. s.n. (SP336024); Anchieta, Praia de Parati, 1-VII-1992 feminina, tetraspórica, S.M.P.B. Guimarães et al. s.n. (SP336467); 16-V-1999, feminina, masculina, tetraspórica, S.M.P.B. Guimarães et al. s.n. (SP355480), Iriri, 1-VII-1985, tetraspórica, S.M.P.B. Guimarães s.n. (SP355481); Piúma, Ilha dos Gambás, 12-III-1986, feminina, masculina, S.M.P.B. Guimarães et al. s.n. (SP355482); Itapemirim, Ilha do Francês, 2-V-1985, feminina, tetraspórica, S.M.P.B. Guimarães et al. s.n. (SP355483); Itaoca/Itaipava, 13-III-1986, feminina, tetraspórica, S.M.P.B. Guimarães et al. s.n. (SP3 18147); Marataízes, 8-III-1986, feminina, masculina, tetraspórica, S.M.P.B. Guimarães et al. s.n. (SP355484), 27-IV-1991, feminina, masculina, tetraspórica, S.M.P.B. Guimarães et al. s.n. (SP355485). S̃̃o PAULO: Ubatuba, Ilha das Couves, 5-XI-1999, feminina, tetraspórica, S.M.P.B. Guimarães et al. s.n. (SP355508); Praia de Itaguá, 16-XI-1997, feminina, S.M.P.B. Guimarães \& N.S. Yokoya s.n. (SP355486); Praia da Fortaleza, 29-V-2002, infértil, S.M.P.B. Guimarães et al. s.n. (SP355487); Ilhabela, Baía dos Castelhanos, Saco do Eustáquio, 15-X-2001, infértil, S.M.P.B. Guimarães et al. s.n. (SP355509); São Sebastião, Praia das Cigarras, 27-V-2002, tetraspórica, infértil, S.M.P.B. Guimarães et al. s.n. (SP355488); Guarujá, Sítio de São Pedro, 6-III-2000, infértil, S.M.P.B. Guimarães et al. s.n. (SP355489); Praia de Pernambuco, 9-VII-1978, tetraspórica, S.M.P.B. Guimarães et al. s.n. (SP355490). 


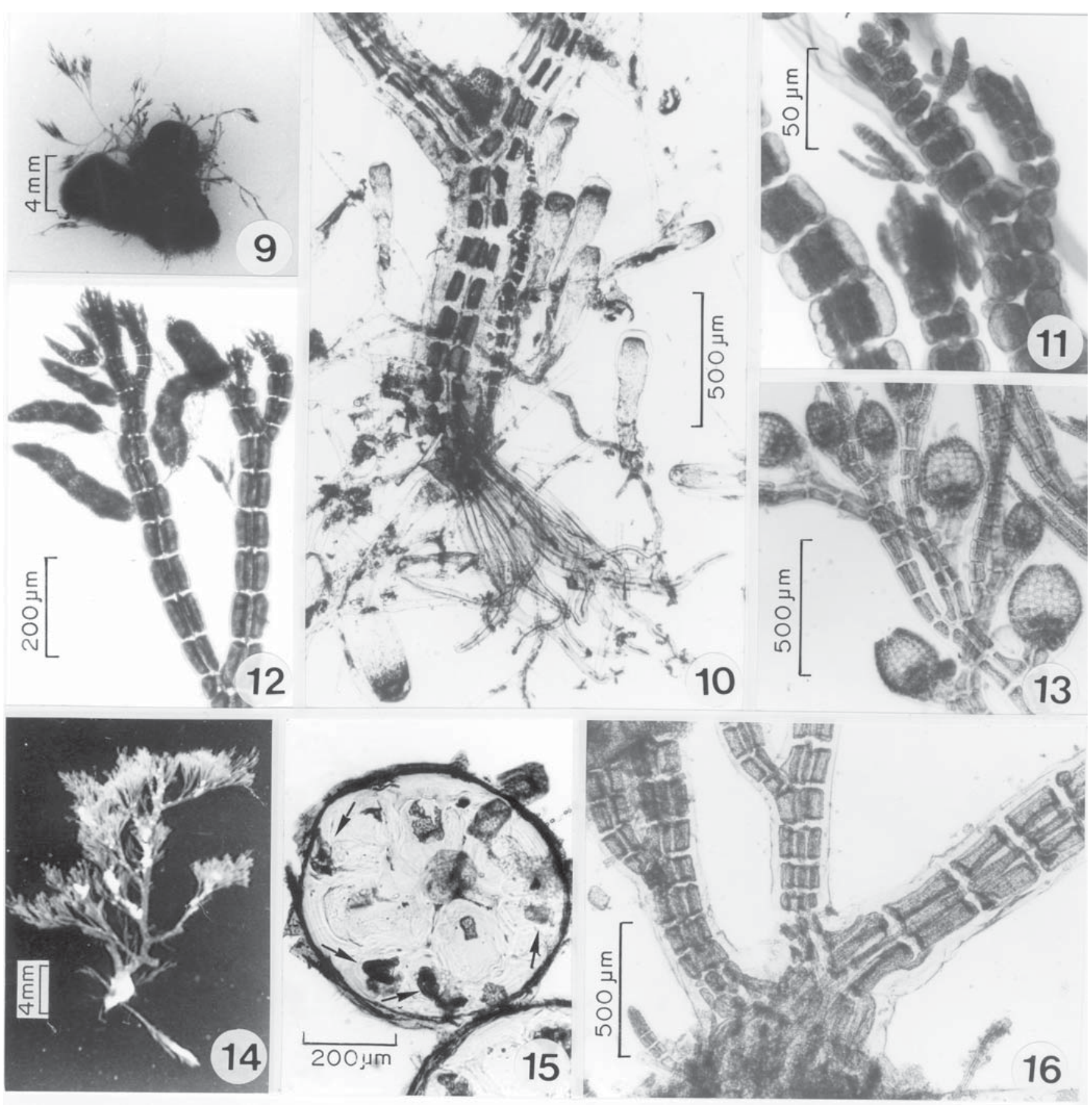

Figuras 9-13. Neosiphonia gorgoniae. 9. Hábito da planta sobre Codium taylorii P.C. Silva. 10. Região basal do talo sobre Codium taylorii, mostrando o disco de fixação formado por um tufo de rizóides. 11. Corpos espermatangiais jovens. 12. Corpos espermatangiais maduros. 13. Fronde com cistocarpos. Figuras 14-16. Neosiphonia harveyi. 14. Hábito. 15. Corte transversal à região basal mostrando as 4 células pericentrais e a corticação (setas). 16. Detalhe da região basal.

Figures 9-13. Neosiphonia gorgoniae. 9. Habit of a plant growing on Codium taylorii P.C. Silva. 10. Basal portion of the plant growing on Codium taylorii, showing attachment disc formed by cluster of rhizoids. 11. Young spermatangial bodies. 12. Mature spermatangial bodies. 13. Frond with cystocarps. Figures 14-16. Neosiphonia harveyi. 14. Habit. 15. Cross section on basal region showing four pericentral cells and cortication (arrows). 16. Aspect of basal region. 
Distribuição: Atlântico: Carolina do Norte, Caribe, (localidade-tipo St. Thomas, Ilhas Virgens), Brasil. Pacífico: Baixa Califórnia, Pacífico tropical, Coréia, Japão. Índico: Maldivas; Seychelles.

Coletada como epífita de Bryocladia, Spyridia, coralináceas articuladas, Acanthophora spicifera (Vahl) Børgesen e Dasya brasiliensis.

Neosiphonia ferulacea e N. sphaerocarpa são consideradas espécies próximas. $N$. sphaerocarpa tem dimensões menores, além de não apresentar segmentos mais largos que altos em toda a extensão do talo. Como já mencionado, somente as plantas coletadas em Barra Seca e na Enseada das Garças (Espírito Santo), que são muito mais robustas, com segmentos nitidamente mais largos que altos, foram consideradas como N. ferulacea.

Na literatura, a separação entre Neosiphonia ferulacea e $N$. sphaerocarpa não é clara. Børgesen (1918), quando propôs a espécie Polysiphonia sphaerocarpa, comentou que esta era muito semelhante a P. ferulacea, diferindo apenas por ser uma planta mais delicada e menor. Em relação às medidas apresentadas por Børgesen (1918), as plantas brasileiras identificadas como N. sphaerocarpa atingem altura maior e diâmetro dos filamentos eretos e prostrados também maior. Schneider \& Searles (1991), comparando as duas espécies (como Polysiphonia), consideraram que, além das dimensões, as células do ostíolo do cistocarpo também servem para separação entre as duas. Em $N$. sphaerocarpa o ostíolo apresenta um anel de células maiores ou do mesmo tamanho em relação às células da região mediana do pericarpo, enquanto em $N$. ferulacea as células do ostíolo são menores que aquelas da região mediana do pericarpo. No material brasileiro de $N$. sphaerocarpa, verificamos que esta característica não é consistente, deixando dúvidas mesmo quando se analisam os cistocarpos maduros, com pericarpo e ostíolo intactos, de um mesmo espécime.

Schneider \& Searles (1991) descreveram para as duas espécies, rizóides originados na parte distal das células pericentrais, o que não concorda com o material brasileiro, onde os rizóides são sempre proximais. A maioria dos autores não menciona a posição dos rizóides, entretanto, de acordo com nossa interpretação, a figura 29 de Kapraun (1977: 320) (como Polysiphonia sphaerocarpa), mostra rizóides proximais, como em nosso material. Yoneshigue \& Villaça (1986) também mencionam rizóides proximais para este táxon (como P. sphaerocarpa).

Os materiais desta espécie referidos por Kapraun \& Norris (1982) e Schneider \& Searles (1991) podem apresentar espermatângios ramificados, o que não foi observado no material brasileiro.

Neosiphonia tepida (Hollenb.) S.M. Guim. \& M.T. Fujii, comb. nov.

Basônimo: Polysiphonia tepida Hollenb., Bull. Torrey Bot. Club. 85:65.1958.

Figuras 23-25.

Plantas crescendo sobre rocha ou epífitas, marrons, com um sistema prostrado derivado de um ápice ereto, fixo por rizóides proximais, dando origem a eixos eretos de crescimento indeterminado de até $3 \mathrm{~cm}$ alt. Eixos prostrados 120-210 $\mu \mathrm{m}$ diâm., com segmentos ecorticados, largura/altura 1:1 ou pouco mais longos que largos, 7-8 células pericentrais. Eixos eretos na região basal 100-125 $\mu \mathrm{m}$ diâm., região mediana 75-105 diâm., segmentos aproximadamente tão largos quanto longos ou pouco mais longos que largos, tricoblastos curtos ou longos, com até 3 dicotomias ou não ramificados. Ramos na axila dos tricoblastos na seqüência de desenvolvimento do ápice. Cicatriz de tricoblastos visível em alguns segmentos dos ramos eretos. Tetrasporângios ca. $50 \mu \mathrm{m}$ diâm., em espiral. Corpos espermatangiais cilíndricos, substituindo um ramo do tricoblasto, 33-40 $\mu \mathrm{m}$ diâm. e 130-150 $\mu \mathrm{m}$ compr. e terminando em uma ou duas células estéreis. Ramo carpogonial com 3 células. Cistocarpos ovóides, 220-250 $\mu \mathrm{m}$ diâm. e 240-270 $\mu \mathrm{m}$ alt. com pedúnculo curto.

Material examinado: BRASIL: EsPírITo SANTO: Vila Velha, Ponta da Fruta, 5-VII-1985, tetraspórica, S.M.P.B. Guimarães et al. s.n. (SP318159); 9-III-1986, feminina, masculina, tetraspórica, S.M.P.B. Guimarães et al. s.n. (SP318143, 318145); Anchieta, Praia de Parati, 3-IX-1994, feminina, tetraspórica, S.M.P.B. Guimarães et al. s.n. (SP294923, 294924, 294927, 294934), 11-VI-1995, feminina, tetraspórica, S.M.P.B. Guimarães et al. s.n. (SP317968), 16-V-1999, feminina, tetraspórica, S.M.P.B. Guimarães et al. s.n. (SP355492); Ponta dos Castelhanos, 16-VI-1999, masculina, S.M.P.B. Guimarães et al. s.n. (SP355491); Itapemirim, Marataízes, 2-IX-1994, masculina, tetraspórica, S.M.P.B. Guimarães et al. s.n. (SP294926). São PaUlo: Ubatuba, Praia do Bonete, 14-III-2001, 7-9 m profundidade, tetraspórica, $G$. Amado Filho et al. s.n. (SP336813).

Distribuição: Atlântico: Carolina do Norte (localidade-tipo Beaufort), Brasil. Pacífico: Hawaí. Índico: Maldivas.

Coletada como epífita de Bryocladia spp., Laurencia spp., Spyridia spp., Cryptonemia spp., 


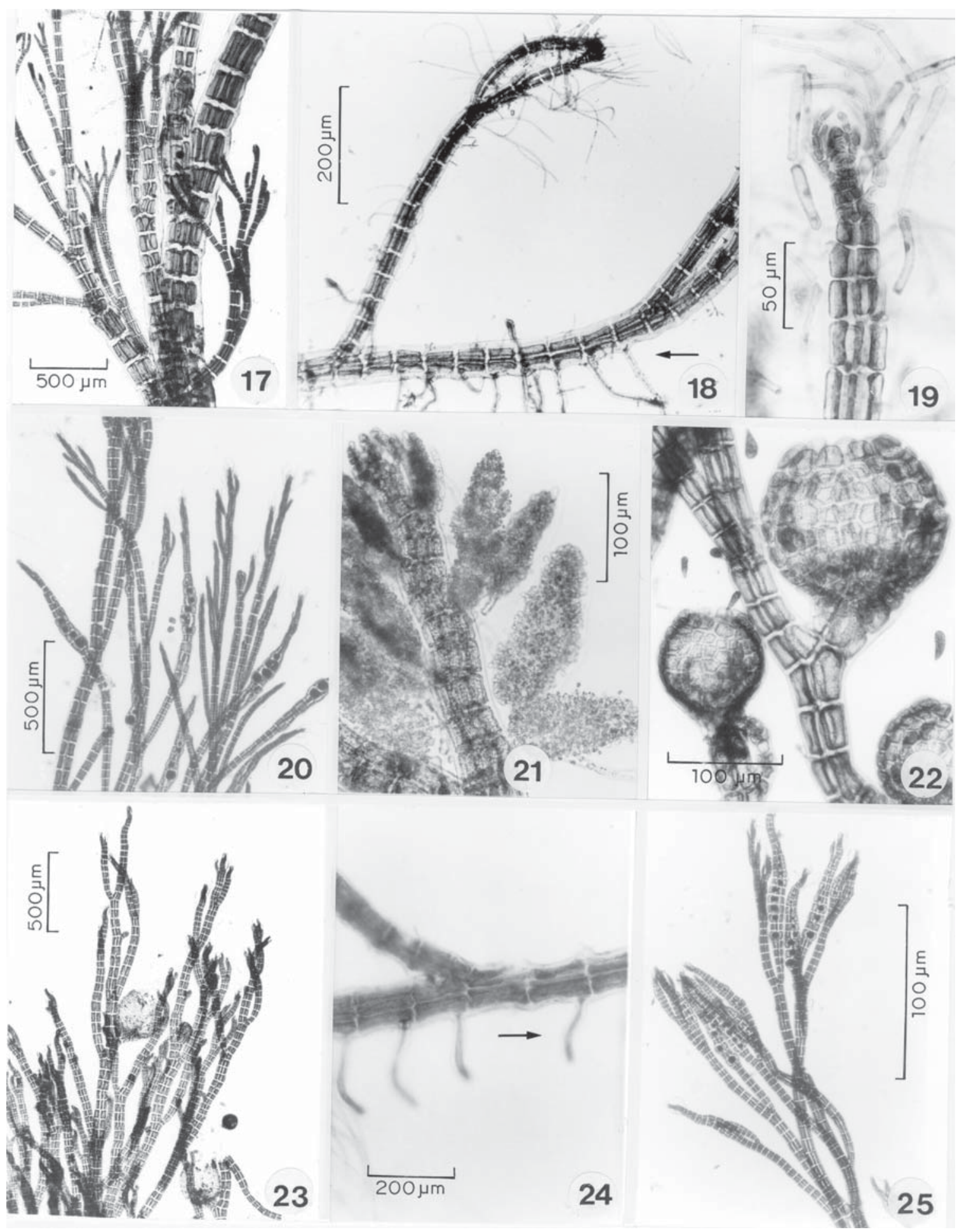

Figuras 17-22. Neosiphonia sphaerocarpa. 17. Hábito. 18. Eixo com parte prostrada, parte ereta e rizóides proximais. A seta indica a direção do ponto de origem do talo. 19. Ápice com tricoblastos. 20. Fronde tetraspórica. 21. Corpos espermatangiais maduros. 22. Detalhe dos cistocarpos mostrando células do ostíolo. Figuras 23-25. Neosiphonia tepida. 23. Planta com cistocarpos. 24. Detalhe dos rizóides proximais. A seta indica a direção do ponto de origem do talo. 25. Fronde tetraspórica.

Figures 17-22. Neosiphonia sphaerocarpa. 17. Habit. 18. Prostrate and erect parts of the axis, and proximal rhizoids. Arrow indicates the direction of thallus origin. 19. Apice with trichoblasts. 20. Tetrasporic plant. 21. Mature spermatangial bodies. 22. Detail of cystocarps showing ostiolar cells. Figures 23-25. Neosiphonia tepida. 23. Cystocarpic plant. 24. Detail of proximal rhizoids. Arrow indicates the direction of thallus origin. 25. Tetrasporic plant. 
Amansia multifida J.V. Lamour. e sobre Pterocladiella capillacea (S.G. Gmel.) Santel. \& Hommers. e Hypnea nigrescens Grev. ex J. Agardh.

Esta espécie é facilmente caracterizada por ser a única, dentre as espécies estudadas, que apresenta 7-8 células pericentrais.

Nossos dados concordam com Oliveira Filho (1969) e Ugadim (1970) (como Polysiphonia tepida). Plantas desta espécie formam tapetes extensos sobre rocha em locais expostos no Espírito Santo, principalmente nos arenitos da Praia de Parati, tolerando um recobrimento moderado de areia. No Estado de São Paulo, a espécie ocorreu em pequena quantidade, crescendo como epífita, com o talo de tamanho reduzido.

\section{Gênero Polysiphonia}

Polysiphonia decussata Hollenb., Amer. J. Bot. 29:780. 1942.

Figuras 26-28.

Plantas essencialmente prostradas com ápice disposto na horizontal, crescendo sobre rochas, fixas por numerosos rizóides com conexão aberta; eixos prostrados com 120-150 $\mu \mathrm{m}$ diâm., os quais originam eixos eretos de crescimento indeterminado de até $0,6 \mathrm{~cm}$ alt., 4 células pericentrais e segmentos mais largos que altos. Eixos eretos sem diferenciação de eixo principal, 80-85 $\mu \mathrm{m}$ diâm. na região basal e 55-75 $\mu \mathrm{m}$ diâm. na região mediana. Ramificação alterno-dística, com ramos de origem exógena dispostos em intervalos de 4 segmentos, não associados aos tricoblastos. Tricoblastos raros, observados em início de desenvolvimento. Célula-cicatriz de tricoblastos ausente. Estruturas reprodutivas não observadas.

Material examinado: BRASIL: EsPírITO SANTO: Anchieta, Praia de Parati, 16-V-1999, infértil, S.M.P.B. Guimarães et al. s.n. (SP355480). São PaUlo: Ubatuba, Ilha das Couves, 5-XI-1999, tetraspórica, S.M.P.B. Guimarães et al. s.n. (SP355506).

Distribuição: Atlântico: Brasil. Pacífico: do sul da Califórnia (localidade-tipo: Los Angeles) à Ilha Guadalupe, Baja California, Ilhas Galápagos. Índico: Ilhas Reunião.

Encontrada emaranhada em tapetes de algas formados por Ophidocladus simpliciusculus (P. Crouan \& H. Crouan) Falkenb. e Neosiphonia sphaerocarpa. À primeira vista, o "aspecto penado" dos ramos curtos pode lembrar uma espécie de Pterosiphonia. Entretanto, a presença de tricoblastos e a ausência de coalescência entre os ramos de crescimento determinado e indeterminado excluem estas plantas do gênero Pterosiphonia. Esta espécie só está referida para o Sudeste do Brasil.

Polysiphonia cf. denudata (Dillwyn) Grev. ex Harvey in Hook., The English flora of Sir James Edward Smith, 5(1):332. 1833.

Figuras 29-33.

Plantas vermelhas, formando tufos isolados, fixos por disco basal, com sistema prostrado reduzido formado secundariamente; rizóides com conexão fechada. Eixos eretos de até $8 \mathrm{~cm}$ alt., segmentos ecorticados, 2,5 a 3,0 vezes mais largos que longos em toda extensão do eixo, 5-6 células pericentrais, 170-250 $\mu \mathrm{m}$ diâm. na região basal e 85-205 $\mu \mathrm{m}$ diâm. na mediana. Tricoblastos raros, curtos ou ausentes. Presença de poucas célulascicatriz de tricoblastos. Ramos saindo da axila dos tricoblastos, na seqüência do desenvolvimento do ápice. Plantas, muitas vezes, apresentando ápices alargados (truncados), com a célula apical retomando, com suas divisões, o crescimento do eixo. Tetrasporângios $80 \mu \mathrm{m}$ diâm., em linha reta. Plantas sexuadas não observadas.

Material examinado: BRASIL: EsPírito SANTO: Itapemirim, Itaoca/Itaipava, 30-VI-1985, tetraspórica, S.M.P.B. Guimarães et al. s.n. (SP355784). São PAUlO: Ubatuba, Ilha da Rapada, 04-IV-1999, 9-12 m profundidade, tetraspórica, P. Horta s.n. (SP355493); Praia da Fortaleza, 29-V-2002, infértil, M.T. Fujii \& S.M.P.B. Guimarães s.n. (SP355494).

Distribuição: Atlântico: da Nova Escócia ao Golfo do México, Caribe, Brasil. Dos Paises Baixos a Portugal, Ilhas Britânicas (localidade-tipo: Southampton), Mediterrâneo. Marrocos. África tropical. Índico: norte do oceano Índico, Ilhas Mauricio, Tanzânia. Pacífico: Austrália.

Coletadas sobre rochas, pedaços de conchas ou como epífitas de coralináceas. Esta espécie é muito característica e é considerada freqüente em locais protegidos, embora tenham sido encontrados poucos espécimes nas amostragens realizadas. $\mathrm{O}$ fato das plantas apresentarem eixos com ápices alargados (truncados) e a célula apical reiniciando o processo de divisão pode significar que a espécie apresente um crescimento sazonal. Conforme será detalhado na discussão final, estas plantas diferem quanto à disposição dos tetrasporângios dos dados de Kapraun (1977) e Maggs \& Hommersand (1993), sendo por isso referidas como Polysiphonia cf. denudata.

No Brasil, a espécie está referida para estados da região Sudeste e Nordeste, o que sugere que possa apresentar distribuição ampla no litoral brasileiro. 


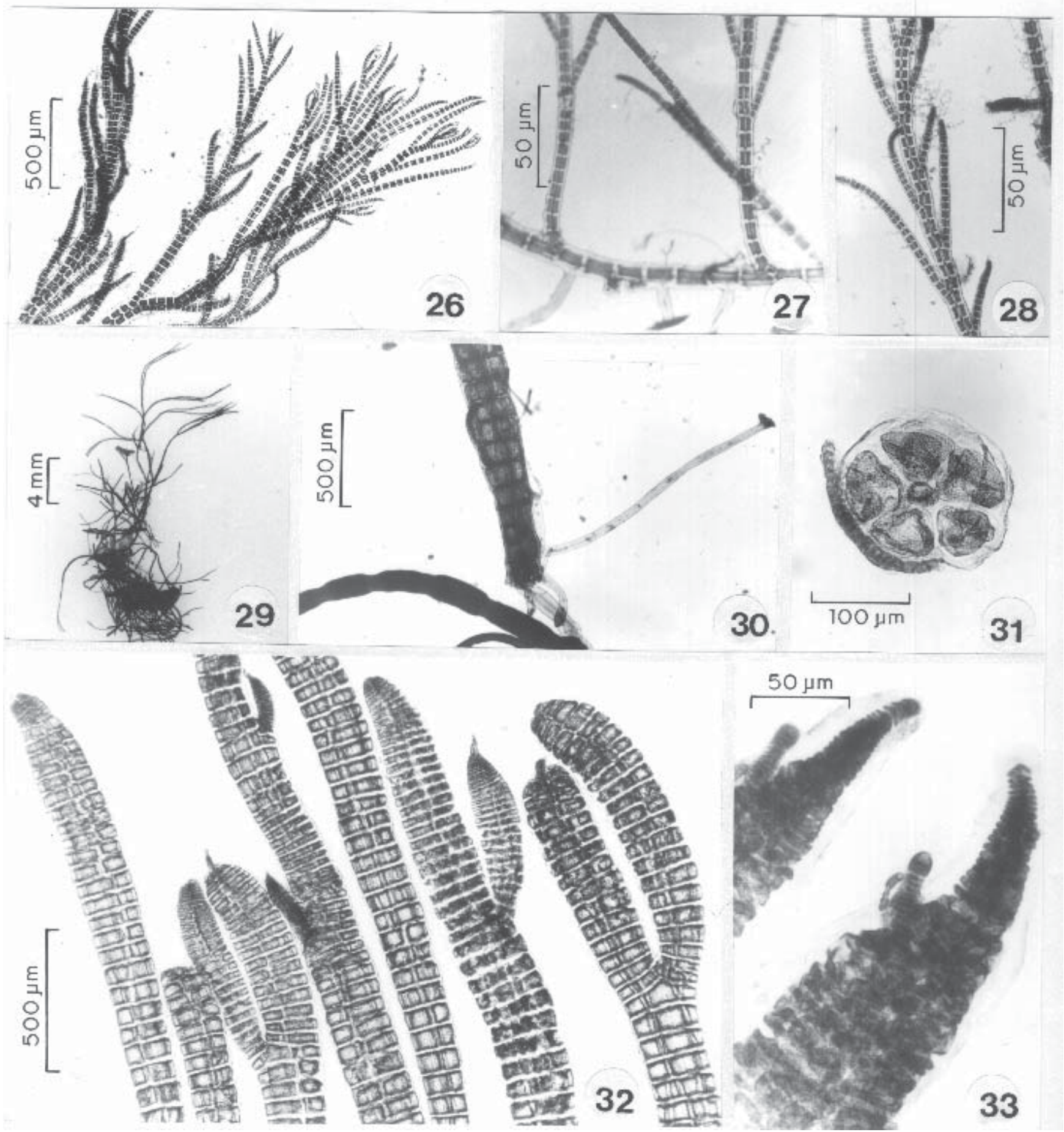

Figuras 26-28. Polysiphonia decussata. 26. Hábito. 27. Eixo prostrado e ramos eretos. 28. Aspecto da região mediana do ramo ereto. Figuras 29-33. Polysiphonia cf. denudata. 29. Hábito. 30. Aspecto da parte basal com rizóides sobre Jania adhaerens J.V. Lamour. 31. Corte transversal à fronde com 5 pericentrais. 32. Ápices alargados com a célula apical reiniciando as divisões. 33. Ápice com ramos laterais originando-se na axila dos tricoblastos.

Figures 26-28. Polysiphonia decussata. 26. Habit. 27. Prostrate and erect axes. 28. Detail of median region of the frond. Figures 29-33. Polysiphonia cf. denudata. 29. Habit. 30. Basal part with rhizoids growing on Jania adhaerens J.V. Lamour. 31. Cross section showing five pericentral cells. 32. Enlarged apices with divisions of apical cell being initiated. 33. Apices with lateral branches forming in the axils of trichoblasts. 
Polysiphonia howei Hollenb. in W.R. Taylor, Allan Hancock Pacific Exped. 12:302. 1945.

Figuras 34-38.

Plantas marrom-escuras, essencialmente prostradas com ápice disposto na horizontal, crescendo sobre rocha e raízes de mangue, associadas principalmente a espécies de Bostrychia. Eixos prostrados 100-170 $\mu \mathrm{m}$ diâm., rizóides distais, segmentos ecorticados, mais largos que longos, com 9-14 células pericentrais. Eixos eretos de até $1,0 \mathrm{~cm}$ alt., curvados em direção ao ápice do eixo prostrado quando jovens, segmentos mais largos

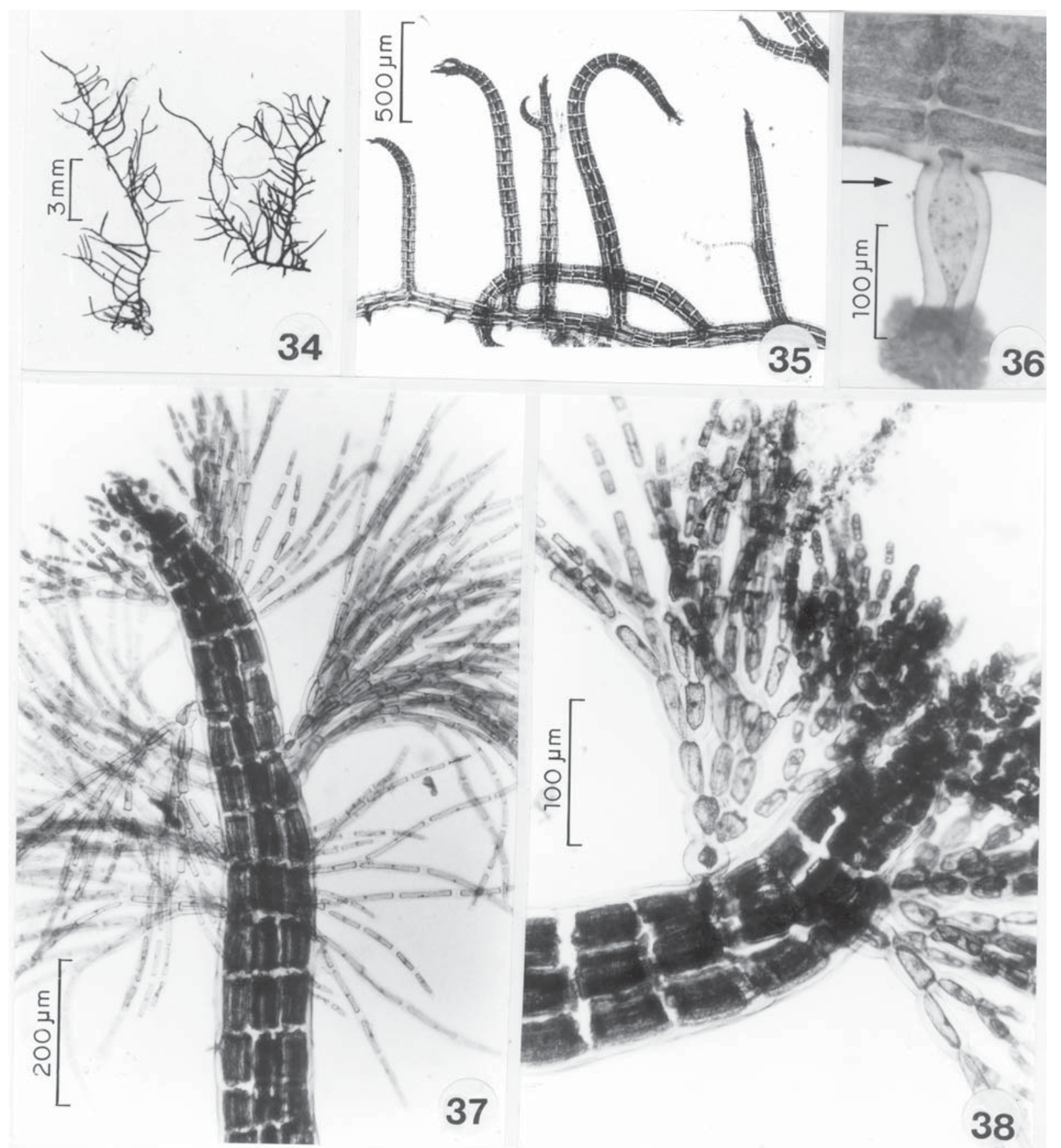

Figuras 34-38. Polysiphonia howei. 34. Hábito. 35. Eixo prostrado e ramos eretos. 36. Detalhe do rizóide distal. A seta indica a direção do ponto de origem do talo. 37. Ápice com tricoblastos. 38. Detalhe dos tricoblastos vendo-se a célula suprabasal espessada.

Figures 34-38. Polysiphonia howei. 34. Habit. 35. Prostrate and erect axes. 36. Detail of distal rhizoid. Arrow indicates the direction of thallus origin. 37. Apices with trichoblasts. 38. Detail of trichoblasts with thickened suprabasal cell. 
que altos, 90-130 $\mu \mathrm{m}$ diâm. na região basal e 100-170 $\mu \mathrm{m}$ diâm. na região mediana; presença de ramos curtos endógenos, inseridos irregularmente; tricoblastos numerosos, longos, com até 3 dicotomias e com célula suprabasal arredondada e com parede espessa. Ramos substituindo tricoblastos na seqüência de desenvolvimento do ápice. Células-cicatriz de tricoblastos raras. Tetrasporângios ca. $75 \mu \mathrm{m}$ diâm., em espiral. Plantas masculinas não observadas. Ramo carpogonial com 4 células. Cistocarpos urceolados, não pedunculados, ca. $550 \mu \mathrm{m}$ diâm. e $600 \mu \mathrm{m}$ alt.

Material examinado: BRASIL: EsPírito SANTO: Aracruz, Praia de Santa Cruz, 17-VIII-1986, infértil, S.M.P.B. Guimarães et al. s.n. (SP355511); Piúma, Ilha dos Gambás, 12-III-1986, tetraspórica, S.M.P.B. Guimarães et al. s.n. (SP336080). São PaUlo: Ubatuba, Ilha das Couves, 5-XI-1999, tetraspórica, S.M.P.B. Guimarães et al. s.n. (SP355503); Praia da Almada, 6-XI-1999, feminina, tetraspórica, S.M.P.B. Guimarães et al. s.n. (SP355504); Praia do Jarobá, 16-V-2000; tetraspórica, M.T. Fujii \& N.S. Yokoya s.n. (SP336683), Ilha Anchieta, 28-V-2002, tetraspórica, S.M.P.B. Guimarães et al. s.n. (SP355479); Cananéia, Ilha do Cardoso, Ponta de Itacuruçá, 15-IV-2002, tetraspórica, S.M.P.B. Guimarães et al. s.n. (SP355507).

Distribuição: Atlântico: Carolina do Norte, Flórida, Caribe, Bermuda, Bahamas (localidade-tipo: Whale Cay, Ilhas Berry), Brasil. Índico: Arquipélago Chagos, Indonésia, Maldivas, Singapura, Somália, Sri Lanka. Pacífico: Havaí, Samoa.

Plantas comuns, encontradas em manguezais, assim como em costões rochosos, em locais sem influência de água doce, formando almofadas densas, geralmente associadas a espécies de Bostrychia. Esta espécie apresenta os sistemas prostrado e ereto muito ramificados e emaranhados. Além dos ramos exógenos, formados a partir dos ápices, verificou-se a presença de ramos curtos, adventícios, endógenos, tanto nos eixos prostrados como nos eretos. No Brasil, a espécie é referida para as regiões Sudeste e Sul, havendo apenas uma citação para o Arquipélago Fernando de Noronha, Estado de Pernambuco (Széchy et al. 1989).

Polysiphonia scopulorum Harv.,Trans. Roy. Irish Acad. 22:540. 1855.

Figuras 39-41.

Plantas essencialmente prostradas com ápice disposto na horizontal, crescendo sobre rocha ou epífitas, marrons ou enegrecidas. Sistema prostrado extenso, dando origem a eixos eretos endógenos de até $0,8 \mathrm{~mm}$ de altura, a cada 3-4 segmentos. Eixos prostrados
55-100 ㅆm diâm., fixos por rizóides com conexão aberta, segmentos ecorticados, mais altos que largos ou tão altos quanto largos e 4 células pericentrais. Ramos eretos saindo unilateralmente do eixo prostrado. Eixos eretos levemente mais estreitos que os prostrados, geralmente sem ramificação ou com ramos adventícios, segmentos mais altos que largos, tricoblastos raros, curtos ou longos, com 1-6 dicotomias. Células-cicatriz de tricoblastos presentes nos ramos eretos. Tetrasporângios ca. 50 um diâm., em linha reta. Plantas masculinas não observadas. Cistocarpos ovóides, 140-220 $\mu \mathrm{m}$ diâm., com pedúnculo curto.

Material examinado: BRASIL: EsPírito SANTo: Aracruz, Enseada das Garças, 5-III-2002, tetraspórica, S.M.P.B. Guimarães s.n. (SP355495); Vila Velha, Ponta da Fruta, 9-III-1986, feminina, tetraspórica, S.M.P.B. Guimarães s.n. (SP355496); Anchieta, Praia de Parati, 16-V-1999, feminina, tetraspórica, S.M.P.B. Guimarães et al. s.n. (SP355492); Iriri, 1-VII-1985, feminina, tetraspórica, S.M.P.B. Guimarães et al. s.n. (SP355497). São Paulo: Ubatuba, Ilha das Couves, 5-XI-1999, tetraspórica, S.M.P.B. Guimarães et al. s.n. (SP355508); Ilha Anchieta, Praia do Presídio, 28-V-2002, tetraspórica, infértil, S.M.P.B. Guimarães et al. s.n. (SP355498).

Distribuição: Atlântico: Caribe, Brasil, Portugal, Espanha, África do Sul. Índico: Austrália (localidadetipo: Fremantle), Kenia, Ilhas Mauricio, Seychelles. Pacífico: Coréia.

Coletada freqüentemente associada a Polysiphonia howei, Ophidocladus simpliciusculus (P. Crouan \& H. Crouan) Falkenb., Herposiphonia secunda (C. Agardh) Ambronn, Lophosiphonia crispata Falkenb. e Chondria sp.

Pode ocorrer certa confusão taxonômica entre Polysiphonia scopulorum e P. atlantica Kapraun \& Norris. Ambas apresentam os filamentos prostrados com ápices sem tricoblastos, dando origem a ramos eretos curtos, a intervalos de 3-4 segmentos e rizóides com conexão aberta com a célula pericentral. De acordo com Hollenberg (1968), P. scopulorum não apresenta células-cicatriz de tricoblastos nos eixos prostrados, a célula apical é inconspícua, os tricoblastos, quando presentes, são altamente ramificados, a maioria dos ramos eretos é de origem endógena, os cistocarpos são esféricos e os ramos espermatangiais ocorrem em pequeno número e terminam em célula estéril. $P$. atlantica apresenta os cistocarpos claramente urceolados, os ramos espermatangiais reunidos nos ápices, as células-cicatriz comuns nos eixos prostrados, as células apicais grandes e conspícuas, a maioria dos 
eixos eretos de origem exógena e os tricoblastos, quando presentes, pouco ramificados.

Plantas pequenas de Polysiphonia subtilissima podem também ser confundidas com $P$. atlantica e P. scopulorum. De acordo com Kapraun et al. (1983), $P$. atlantica e $P$. scopulorum apresentam, nos eixos prostrados, desenvolvimento unilateral dos ramos, produzindo um hábito dorsiventral, enquanto P. subtilissima apresenta um padrão radial de desenvolvimento dos eixos no sistema prostrado. Hollenberg (1968) listou três variedades para esta espécie, porém, autores recentes não as consideram (Abbott 1999).

Polysiphonia subtilissima Mont., Ann. Sci. Nat., Bot., ser. 2, 13:199. 1840.

Figuras 42-46.

Plantas essencialmente prostradas com ápice disposto na horizontal, marrons ou enegrecidas, formando tapetes densos sobre rocha ou emaranhadas a outras algas. Eixos prostrados com 60-85 $\mu \mathrm{m}$ diâm., presos por rizóides com conexão aberta. Ápices indivisos ou bifurcados originando ramos por divisão exógena da célula subapical. Segmentos ecorticados, mais longos que largos, com 4 células pericentrais. Eixos prostrados originando, endogenamente, eixos eretos dispostos em várias direções e eixos prostrados adicionais. Eixos eretos levemente mais estreitos que os prostrados, ramificados, ramos substituindo tricoblastos na seqüência de desenvolvimento do ápice. Ramos adventícios também presentes sobre os eixos eretos. Tricoblastos usualmente ausentes ou raros, curtos, não ramificados. Célula-cicatriz de tricoblastos ausente. Tetrasporângios ca. 50 um diâm., em linha reta. Plantas sexuadas não encontradas.

Material examinado: BRASIL: EsPíRITO SANTO: São Mateus, Barra Nova, 8-XI-1989, infértil, S.M.P.B. Guimarães et al. s.n. (SP355743); Serra, Nova Almeida, 17-V-1999, mangue do Rio Reis Magos, tetraspórica, S.M.P.B. Guimarães et al. s.n. (SP355499); Piúma, Ilha dos Gambás, 30-VI-1985, infértil, S.M.P.B. Guimarães et al. s.n. (SP318158). SÃo PAULO: Itanhaém, Cibratel, 30-X-2001, infértil, N.S. Yokoya \& C. Guido s.n. (SP336814); Iguape, Ponta do Grajaúna, 20-IX-2002, tetraspórica, S.M.P.B. Guimarães et al. s.n. (SP355501); Cananéia, Ilha do Cardoso, costão do Pereirinha, 13-IV-2002, infértil, S.M.P.B. Guimarães et al. s.n. (SP355500); Ilha da Casca, 13-IV-2002, infértil, S.M.P.B. Guimarães et al. s.n. (SP355510).

Distribuição: Atlântico: nordeste da América do
Norte até o Caribe, Guiana Francesa (localidade-tipo: Caiena), Brasil. África tropical. Pacífico: Austrália, Hawai. Índico: Ilhas Aldabra, Austrália, Índia, Kenia, Mauricio, Seychelles, África do Sul.

Espécie coletada em associação com cianofíceas, Caloglossa leprieurii (Mont.) G. Martens e Bostrychia radicans (Mont.) Mont. in Orbigny, no manguezal da Ilha do Cardoso e, também, associada com Ptilothamnion speluncarum (Collins \& Herv.) D.L. Ballant. \& M.J. Wynne e com espécies de Ceramium.

De acordo com Womersley (1979), Polysiphonia subtilissima e $P$. scopulorum são espécies de ampla distribuição. $P$. subtilissima é encontrada freqüentemente em áreas de salinidade reduzida. É a espécie mais amplamente distribuída no litoral brasileiro, sendo referida praticamente em todos os trabalhos de flora, desde o Maranhão até o Rio Grande do Sul.

Ugadim (1970, 1976) referiu Polysiphonia macrocarpa para a praia do Pereirinha, foz do rio Perequê, na Ilha do Cardoso (SP). Neste local, coletamos material abundante de P. subtilissima. Esta autora usou a quantidade de tricoblastos como caráter para separar $P$. subtilissima de $P$. macrocarpa, o que, conforme mencionado na discussão deste trabalho, não se constitui em caráter consistente. Portanto, o material referido por Ugadim $(1970,1976)$ como $P$. macrocarpa deve corresponder a $P$. subtilissima.

Polysiphonia macrocarpa Harv. in Mackay (1836) foi referida para Bermudas, Carolina do Norte, Flórida, Ilhas Virgens e Barbados (Taylor 1960, Kapraun 1977). Entretanto, Kapraun \& Norris (1982) propuseram um nome novo para este táxon, Polysiphonia atlantica Kapraun \& Norris, pois o nome P. macrocarpa Harv. in Mackay (1836) é inválido (Womersley 1979), sendo um homônimo tardio de P. macrocarpa (C. Agardh) Spreng.

\section{Discussão}

Os estudos detalhados e a reavaliação das características morfológicas utilizadas na identificação das espécies de Polysiphonia sensu lato, que ocorrem nos Estados do Espírito Santo e São Paulo, levaram ao reconhecimento de 11 espécies (tabela 1).

O caráter ramo carpogonial com três ou quatro células foi verificado em quatro espécies, Neosiphonia gorgoniae, $N$. sphaerocarpa, $N$. tepida e Polysiphonia howei (figuras 47-50).

Dentre as espécies estudadas, Neosiphonia gorgoniae e $N$. tepida enquadram-se dentro da circunscrição do gênero Neosiphonia, apresentando 


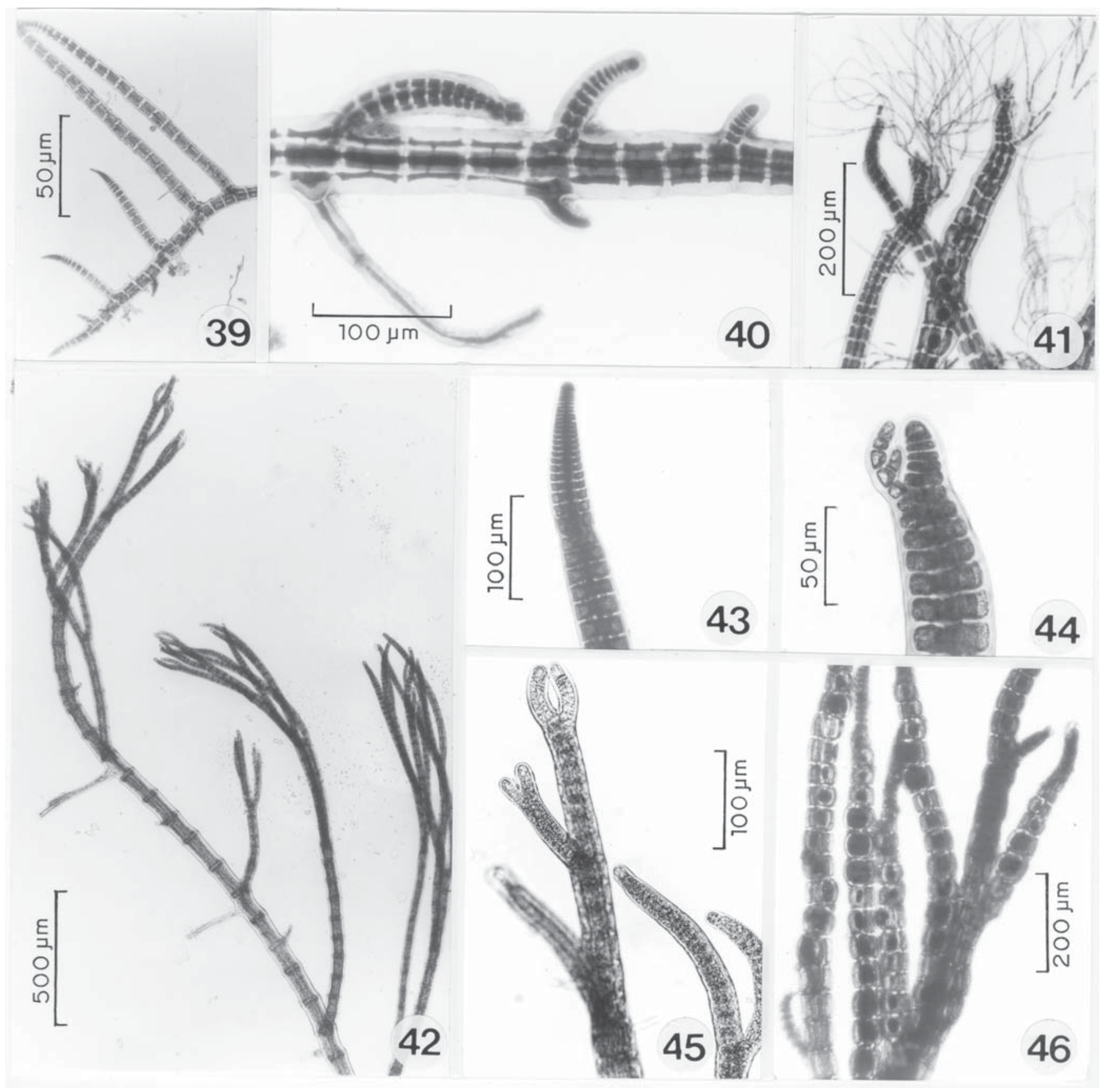

Figuras 39-41. Polysiphonia scopulorum. 39. Eixo prostrado com ápice de crescimento. 40. Eixo prostrado com ramos eretos endógenos e rizóides. 41. Ápice de planta tetraspórica com tricoblastos. Figuras 42-46. Polysiphonia subtilissima. 42. Aspecto do eixo prostrado, ramos eretos e rizóides. 43. Ápice simples, indiviso. 44. Ápice de planta tetraspórica com tricoblasto em início de formação. 45. Ápice dividido com as duas células apicais. 46. Detalhe dos tetrasporângios.

Figures 39-41. Polysiphonia scopulorum. 39. Prostrate axis with growing apex. 40. Prostrate axis with endogenous branches and rhizoids. 41. Apices with trichoblasts. Figuras 42-46. Polysiphonia subtilissima. 42. Aspect of prostrate axis, erect branches and rhizoids. 43. Simple undivided apex. 44. Apex with trichoblast in early stage of formation. 45. Divided apex with two apical cells. 46. Detail of tetrasporangia. 

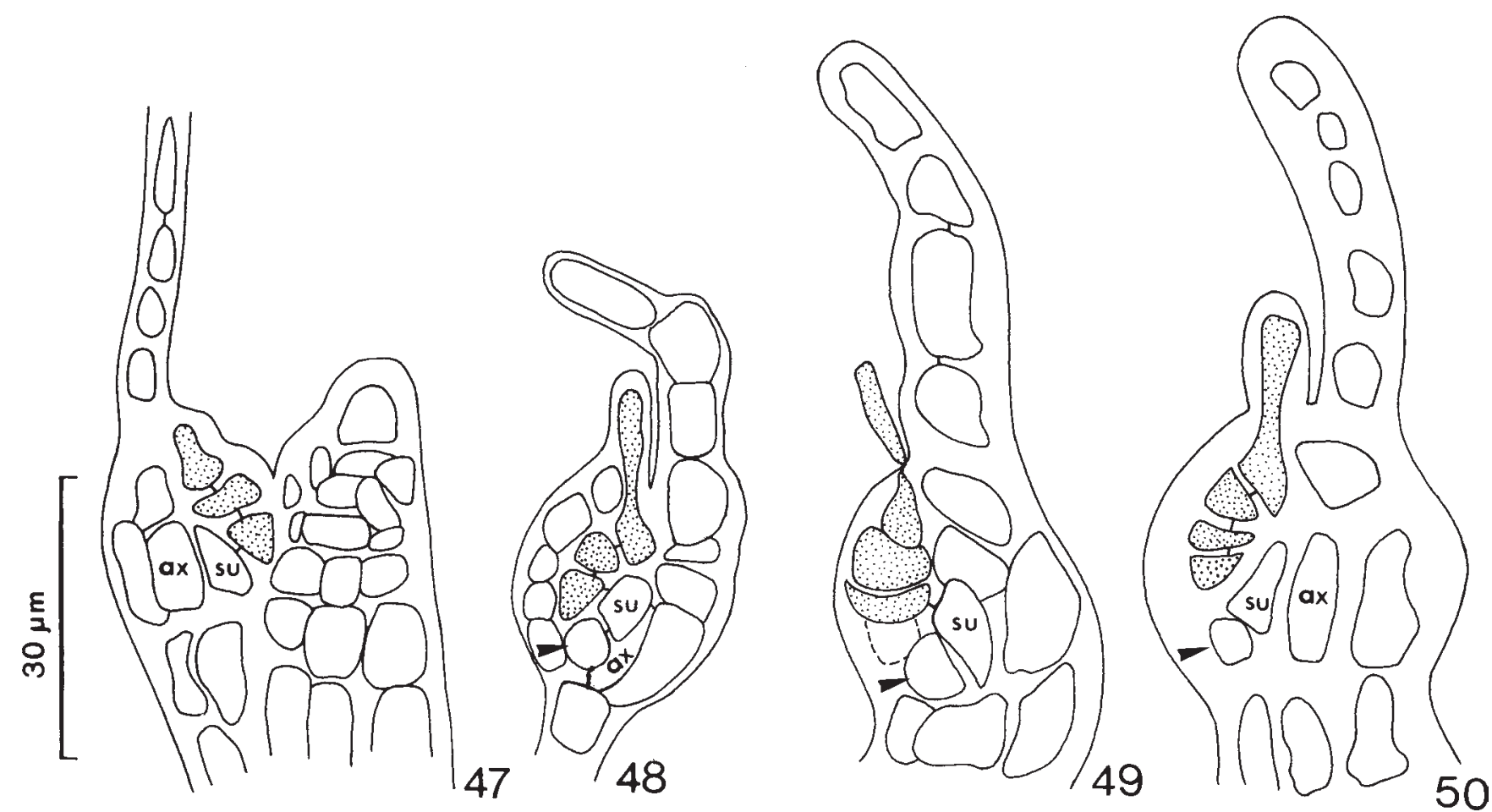

Figuras 47-50. Ramo carpogonial com 3 células em espécies de Neosiphonia. 47. N. gorgoniae. 48 N. sphaerocarpa. 49. N. tepida. 50. Polysiphonia howei. Ramo carpogonial com 4 células. Células pontilhadas representam o ramo carpogonial. A seta indica um ramo estéril originado da célula sustentadora; ax = célula axial; su = célula sustentadora.

Figures 47-50. Carpogonial branches with 3 cells in Neosiphonia species. 47. N. gorgoniae. 48. N. sphaerocarpa. 49. $N$. tepida. 50. Polysiphonia howei. Carpogonial branch with 4 cells. Carpogonial branch cells are dotted. Arrow indicates a sterile branch of the supporting cell; ax = axial cell; su = supporting cell.

iniciais de ramos laterais e de tricoblastos produzidos em segmentos sucessivos, ausência de sistema prostrado ou sistema prostrado derivado a partir de um ápice ereto, rizóides com conexão fechada, tricoblastos abundantes, ramo carpogonial com três células, ramos espermatangiais originados a partir de um ramo do tricoblasto e tetrasporângios dispostos em espiral. Apesar do ramo carpogonial não ter sido observado em $N$. ferulacea, os demais aspectos diagnósticos estão de acordo com o proposto para o gênero. Desta maneira, estão sendo propostas as novas combinações para essas três espécies.

As outras três espécies estudadas, Neosiphonia flaccidissima, $N$. harveyi e N. sphaerocarpa, tiveram as características confirmadas, corroborando a transferência dessas espécies para Neosiphonia, conforme as propostas de Kim \& Lee (1999) e Choi et al. (2001).

De acordo com os resultados obtidos, complementados com dados de literatura (Joly 1957, Yoneshigue 1985, Womersley 1979), Polysiphonia decussata, P. scopulorum e P. subtilissima enquadram-se no conceito atual de Polysiphonia (Kim \& Lee 1999), embora, no presente trabalho, os ramos carpogoniais não tenham sido observados.

Polysiphonia cf. denudata e $P$. howei apresentaram uma combinação de características de Neosiphonia e Polysiphonia, tornando problemática a sua inclusão em um ou em outro gênero. Polysiphonia cf. denudata apresenta ausência de sistema prostrado, rizóide com conexão fechada, ramos espermatangiais originandose de um ramo do tricoblasto (características de Neosiphonia) e, adicionalmente, tetrasporângios em linha reta (característica de Polysiphonia). Kapraun (1977) e Maggs \& Hommersand (1993) descreveram tetrasporângios dispostos em espiral para $P$. denudata da Carolina do Norte, EUA, e das Ilhas Britânicas, respectivamente. No presente trabalho esta espécie está sendo referida como $P$. cf. denudata devido à diferença encontrada quanto à disposição dos tetrasporângios, embora, no Brasil, a espécie já venha sendo identificada como $P$. denudata por alguns autores (Oliveira Filho 1969, Yoneshigue 1985, Horta 2000).

Polysiphonia howei apresenta sistema prostrado 


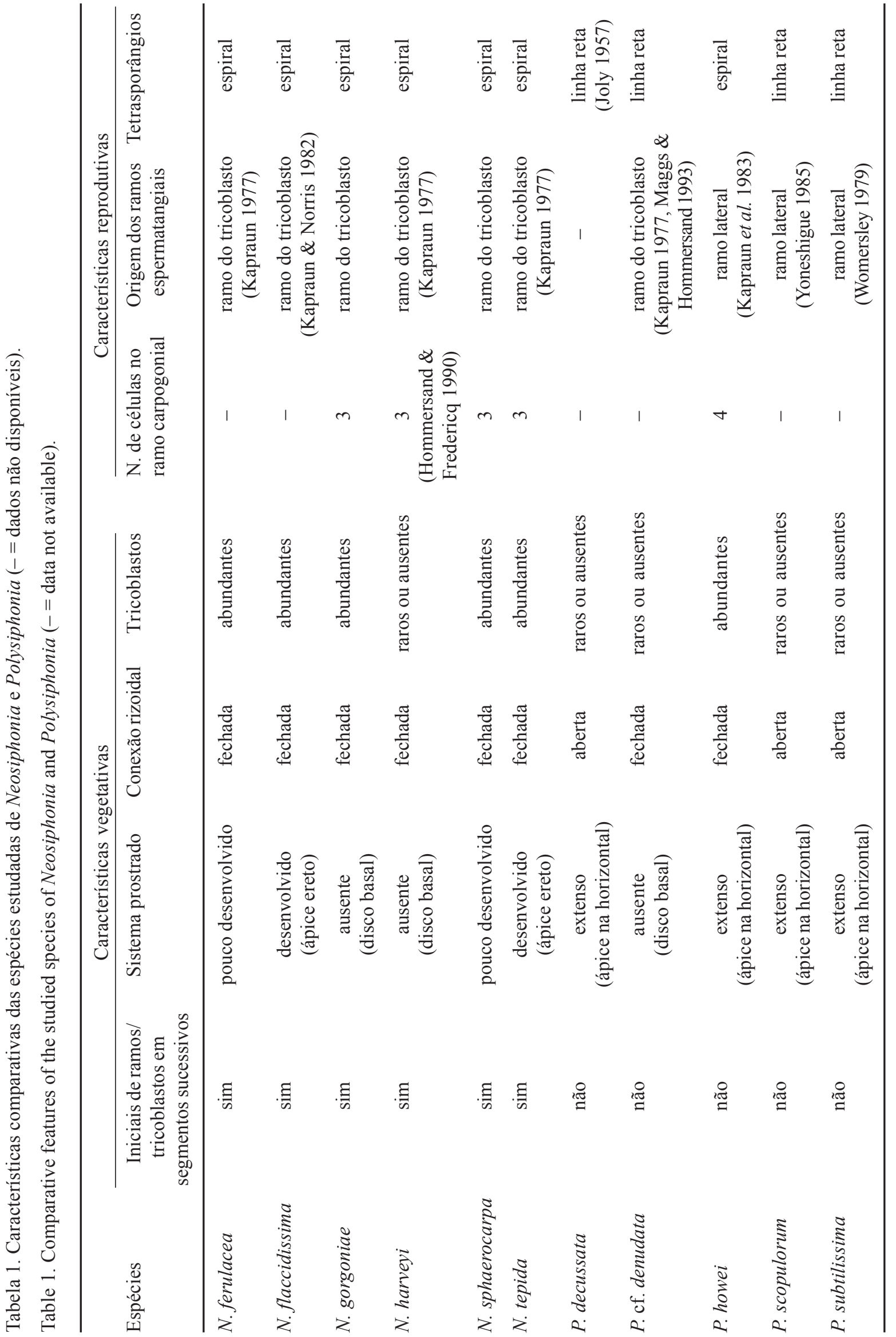


bem desenvolvido, ramo carpogonial com quatro células (Figura 50), ramos espermatangiais originados de iniciais de ramos laterais (características de Polysiphonia) e, adicionalmente, rizóide com conexão fechada e tetrasporângios em espiral (características de Neosiphonia). Além disso, P. howei apresenta 9-14 células pericentrais por segmento axial, discordando do conceito de Neosiphonia (Kim \& Lee 1999), que engloba espécies com quatro a nove células pericentrais por segmento axial.

A ocorrência de espécies com características de ambos os gêneros não invalida a proposta de Kim \& Lee (1999), uma vez que a mesma pode ser aplicada para a maioria das espécies estudadas (tabela 1). Posteriormente, quando dados adicionais estiverem disponíveis, a posição taxonômica de Polysiphonia cf. denudata e $P$. howei poderá ser esclarecida.

Choi et al. (2001) reavaliaram as afinidades filogenéticas de Polysiphonia sensu lato, baseando-se na análise cladística combinada de caracteres anatômicos e de sequenciamento da subunidade pequena do DNA ribossomal e concluíram que Polysiphonia sensu lato consiste de três clados bem distintos: Polysiphonia, Neosiphonia e um terceiro clado com características mistas de Polysiphonia e de Neosiphonia.

Com base nas amostras de Polysiphonia e Neosiphonia analisadas, concluímos que para a taxonomia do grupo, as características relacionadas aos tricoblastos não são consistentes, pois estes podem ser abundantes ou raros, estar em início de desenvolvimento ou completamente ausentes. A variação apresentada em uma mesma espécie está, provavelmente, associada com a idade da planta e com a sazonalidade (Kapraun 1977). Por exemplo, em algumas amostras de Neosiphonia sphaerocarpa de Ubatuba, SP (Praia da Fortaleza e Praia das Cigarras, maio/2002, Praia de Itaguá, novembro/1997), os tricoblastos estavam totalmente ausentes. Em outras amostras desta mesma espécie (Ilha dos Gambás (ES), março/1986 e Ilha das Couves (SP), maio/1999), os tricoblastos e as células-cicatriz dos mesmos estavam presentes na maioria dos segmentos dos ramos eretos. Esta variação faz com que os tricoblastos sejam considerados com ressalvas na taxonomia e que sejam analisadas amostras de diferentes locais e épocas. Maggs \& Homersand (1993) referiram em Polysiphonia denudata tricoblastos numerosos originados em cada segmento, enquanto que Kapraun (1977) referiu poucos tricoblastos para a mesma espécie. A presença de células cicatriz de tricoblastos nos eixos prostrados foi referida para
P. atlantica (Hollenberg 1968), porém, não foi registrada em nenhum dos táxons aqui estudados. $\mathrm{O}$ tamanho das células do ostíolo do cistocarpo em relação às demais células do pericarpo, que tem sido empregado para separar espécies (Schneider \& Searles 1991), não é uma característica consistente.

O grau de desenvolvimento do sistema prostrado e ereto constitui-se em caráter importante e as espécies estudadas puderam ser classificadas de acordo com os padrões estabelecidos por Kapraun (1977): 1. Neosiphonia ferulacea, N. gorgoniae, N. harveyi, N. sphaerocarpa e Polysiphonia cf. denudata apresentam eixos inicialmente eretos a partir de uma base discóide, mas formam uma fixação secundária a partir de ramos inferiores dos eixos eretos que se tornam decumbentes. De acordo com Kapraun et al. (1983), $N$. ferulacea e $N$. sphaerocarpa apresentam inicialmente uma base discóide que é logo obscurecida; 2. N. flaccidissima e N. tepida apresentam talos que desenvolvem um sistema horizontal a partir de um ápice ereto; 3. P. decussata, P. howei, P. scopulorum e $P$. subtilissima apresentam um sistema essencialmente prostrado a partir de um ápice horizontal. De acordo com Kim \& Lee (1999), no gênero Neosiphonia podem ocorrer os dois primeiros tipos de desenvolvimento.

Os caracteres taxonômicos consistentes para separação das espécies de Neosiphonia e Polysiphonia, em nosso conceito, são: número de células pericentrais, modo de origem do rizóide, hábito da planta (com sistema prostrado ou com disco de fixação), presença ou não de corticação, proporção altura/largura dos segmentos e padrão de ramificação.

Através deste trabalho, verificou-se que os mesmos táxons ocorrem nos Estados do Espírito Santo e São Paulo, com exceção de Neosiphonia harveyi que foi encontrada em uma única coleta no Estado de São Paulo. Esta espécie tem sido considerada como integrante da flora temperada fria do Atlântico norte (Kapraun 1977). Entretanto, podemos inferir que as 11 espécies estudadas devem estar distribuídas em toda região Sudeste do Brasil. Polysiphonia eastwoodae e P. saccorhiza, citadas para a região de Cabo Frio (Yoneshigue 1985, Yoneshigue \& Villaça 1986), não foram encontradas em nossas amostragens dos Estados de São Paulo e Espírito Santo. De acordo com os autores, P. eastwoodae é uma planta muito rara, vivendo em locais abrigados, banhados por águas quentes, epífita de outras algas e de hidrozoários. P. saccorhiza foi referida pela primeira vez para o Brasil (Atol das Rocas) por Oliveira Filho \& Ugadim (1974) e, posteriormente, para o Rio de Janeiro. As espécies estudadas foram encontradas, 
principalmente, na região entremarés em costões rochosos ou em recifes de arenito, em locais com hidrodinamismo moderado ou em locais protegidos. Em regiões de manguezal foram coletadas Polysiphonia howei, $P$. scopulorum e $P$. subtilissima que também foram encontradas em ambientes marinhos sem influência de água doce. Poucas espécies ocorreram formando populações nítidas ocupando uma extensão considerável dos substratos. Nesta condição encontramos Neosiphonia ferulacea, em Barra Seca e na Enseada das Garças (ES), N. tepida, na Praia de Parati (ES), N. sphaerocarpa na Praia de Parati (ES) e na Ilha das Couves (SP), $N$. howei no manguezal próximo à Santa Cruz (ES) e na praia do Presídio, Ilha Anchieta (SP) e P. subtilissima no manguezal do rio Reis Magos (ES) e na Ilha do Cardoso (SP). Na grande maioria das coletas, as espécies estavam representadas por poucos indivíduos, crescendo como epífitas ou associados com outras algas. Neosiphonia flaccidissima, N. sphaerocarpa e Polysiphonia cf. denudata foram também coletadas no infralitoral.

Agradecimentos - Este trabalho foi parcialmente financiado pela Fapesp, dentro do Programa Biota (Proc. 98/4955-3) e pelo $\mathrm{CNPq}$ - Biodiversidade de algas marinhas bentônicas do litoral brasileiro (Proc. 520748/97-2). S.M.P.B. Guimarães agradece ao CNPq (Proc. 303178/76) e à Fapesp (Proc. 99/04374-3 e 01/05643-0) pela concessão de bolsa e auxílios.

\section{Referências bibliográficas}

ABBOTT, I.A. 1999. Marine red algae of the Hawaiian Islands. Bishop Museum Press, Honolulu.

AMADO FILHO, G.M. 1991. Algas marinhas bentônicas do litoral de Saquarema a Itacoatiara (RJ). Dissertação de mestrado, Universidade Federal do Rio de Janeiro, Rio de Janeiro.

BØRGESEN, F. 1918. The marine algae of the Danish West Indies, part 3: Rhodophyceae (4). Dansk Botanisk Arkiv 3:241-304.

CHOI, H.-G., KIM, M.-S., GUIRY, M.D. \& SAUNDERS, G.W. 2001. Phylogenetic relationships of Polysiphonia (Rhodomelaceae, Rhodophyta) and its relatives based on anatomical and nuclear small-subnit rDNA sequence data. Canadian Journal of Botany 79:1465-1476.

FIGUEIREDO, M.A.O. 1989. Ficoflora marinha bentônica do Município de Paraty, Rio de Janeiro. Dissertação de mestrado, Universidade Federal do Rio de Janeiro, Rio de Janeiro.

HOLLENBERG, G.H. 1942. An account of the species of Polysiphonia on the Pacific coast of North America. I. Oligosiphonia. American Journal of Botany 29:772-785.

HOLLENBERG, G.H. 1968. An account of the species of Polysiphonia of the Central and Western Tropical Pacific Ocean. I. Oligosiphonia. Pacific Science 22:56-98.
HOMMERSAND, M.H. \& FREDERICQ, S. 1990. Sexual reproduction and cystocarp development. In Biology of the red algae (K.M. Cole \& R.G. Sheath, eds.). Cambridge University Press, New York, p. 305-345.

HORTA, P.A. 2000. Macroalgas do infralitoral do Sul e Sudeste do Brasil: taxonomia e biogeografia. Tese de doutorado, Universidade de São Paulo, São Paulo.

JOLY, A.B. 1957. Contribuição ao conhecimento da flora ficológica da Baía de Santos e arredores. Boletim da Faculdade de Filosofia, Ciências e Letras da Universidade de São Paulo, série Botânica 14:1-199.

JOLY, A.B. 1965. Flora Marinha do litoral Norte do Estado de São Paulo e regiões circunvizinhas. Boletim da Faculdade de Filosofia, Ciências e Letras da Universidade de São Paulo, série Botânica 21:1-393.

KAPRAUN, D.F. 1977. The genus Polysiphonia in North Carolina, USA. Botanica Marina 20:313-331.

KAPRAUN, D.F. 1979. The genus Polysiphonia (Ceramiales, Rhodophyta) in the vicinity of Port Aransas, Texas. Contributions in Marine Science 22:105-120.

KAPRAUN, D.F. \& NORRIS, J.N. 1982. The red alga Polysiphonia Greville (Rhodomelaceae) from Carrie Bow Cay and Vicinity, Belize. In The Atlantic Barrier Reef Ecosystem at Carrie Bow Cay, Belize, 1: Structure and Communities (K. Rätzler \& I.G. Macintyre, eds.). Smithsonian Contributions to the Marine Sciences 12:225-238.

KAPRAUN, D.F., LEMUS, J.A. \& BULA-MEYER, G. 1983. Genus Polysiphonia (Rhodophyta, Ceramiales) in the Tropical Western Atlantic I. Colombia and Venezuela. Bulletin of Marine Science 33:881-898.

KIM, M.S. \& LEE, I.K. 1999. Neosiphonia flavimarina gen. et sp. nov. with a taxonomic reassessment of the genus Polysiphonia (Rhodomelaceae, Rhodophyta). Phycological Research 47:271-281

MACKAY, J.T. 1836. Flora hibernica III. Algae. William Curry Jun. and Company, Dublin.

MAGGS, C.A. \& HOMMERSAND, M.H. 1993. Seaweeds of the British Isles. Rhodophyta. Ceramiales. v.1, part 3A, HMSO, London.

OLIVEIRA FILHO, E.C. 1969. Algas marinhas do sul do Estado do Espírito Santo (Brasil). I. Ceramiales. Boletim da Faculdade de Filosofia, Ciências e Letras da Universidade de São Paulo, série Botânica 26:1-277.

OLIVEIRA FILHO, E.C. 1977. Algas marinhas bentônicas do Brasil. Tese de livre-docência, Universidade de São Paulo, São Paulo.

OLIVEIRA FILHO, E.C. \& UGADIM, Y. 1974. Novas referências de algas marinhas bentônicas para a flora brasileira. Boletim de Botânica da Universidade de São Paulo 2:71-91.

SCHNEIDER, C.W. \& SEARLES, R.B. 1991. Seaweeds of the Southeastern United States. Cape Hatteras to Cape Canaveral. Duke University Press, Durham. 
SZÉCHY, M.T., NASSAR, C.A.G., FALCÃO, C. \& MAURAT, M.C.S. 1989. Contribuição ao inventário das algas marinhas bentônicas de Fernando de Noronha. Rodriguesia 67:53-61.

TAYLOR, W.R. 1960. Marine algae of the eastern tropical and subtropical coasts of the Americas. University of Michigan Press, Ann Harbor.

UGADIM, Y. 1970. Algas marinhas bentônicas do litoral sul do Estado de São Paulo e do litoral do Estado do Paraná. Tese de doutorado, Universidade de São Paulo, São Paulo.

UGADIM, Y. 1976. Ceramiales (Rhodophyta) do litoral sul do Estado de São Paulo e do litoral do Estado do Paraná (Brasil). Boletim de Botânica da Universidade de São Paulo 4:133-172.
WOMERSLEY, H.B.S. 1979. Southern Australian species of Polysiphonia Greville (Rhodophyta). Australian Journal of Botany 27:459-528.

YONESHIGUE, Y. 1985. Taxonomie et ecologie des algues marines dans la region de Cabo Frio (Rio de Janeiro, Brésil). Thèse de Docteur d'État-Sciences, L'Université d'Aix-Marseille II, Marseille.

YONESHIGUE, Y. \& VILLAÇA, R.C. 1986. Flora marinha da região de Cabo Frio (Estado do Rio de Janeiro, Brasil). 6. Pterosiphonia spinifera, Polysiphonia eastwood, P. flacidissima, P. sphaerocarpa e Streblocladia corymbifera (Rhodomelaceae, Rhodophyta). Novas ocorrências para a costa brasileira. Rickia 13:97-111. 